\title{
Precision, accuracy and meaning of fission track ages*
}

\author{
G POUPEAU \\ Centre des Faibles Radioactivities Laboratoire Mixte CNRS/CEA 91190 Gif-sur \\ Yvette, France \\ Present Address: \\ Centro Brasileiro de Pesquisas Fisicas, Av. Wenceslan Braz, 71 Rio de Janciro, Brazil
}

Abstract. The precision, meaning, and accuracy of the fission track (FT) dating method are reviewed from an examination of the recent literature as well as previously unpublished data from the author's laboratory.

It is concluded that for apparent FT ages (i.e. ages derived from the canonical age equation) a precision ( $2 \sigma$ level) of the order of $\pm 4 \%$ to $\pm 5 \%$ can be reached provided that (i) uranium is sufficiently homogeneously distributed in the dated samples, at least locally; and (ii) a large enough number of tracks can be counted.

Model $\mathrm{FT}$ ages, i.e. ages for which partial geological track annealing is taken into account, have variable degrees of precision. While model ages obtained with the track-size method seem, as evaluated from the literature, to have usually a limited precision of the order of $t 30 \%(2 \sigma)$, plateau ages usually have a precision better than $上 5 \%$ at a $2 \sigma$ confidence level. Because it provides an objective test on the accuracy of track icentification, as well as some insight of the variability of closing temperatures between various samples of a given mineral phase, the Isochronal Plateau (ICP) method, when applicable, will be preferred (Poupeau et al 1980a). However, for phases which could be damaged by heating at relatively high tenperatures, as for example hydrated glass shards from tephra, an Isothermal Plateau (ITP) approach is to be preferred.

Due to uncertainties about the value of the ${ }^{298} \mathrm{U}$ spontaneous fission decay constant $\lambda_{f}$, as well as difficulties inherent in the dosimetry of thermal neutrons in nuclear reactors, the FT method of dating is not an independent one. Presently, it relies on the existence of geological standards (volcanic rocks) of knowln age, allowing to determine an operational ' $\lambda_{f}$ ' value (Naeser et al 1980). Accordingly, the accuracy of an FT age is limited by the accuracy on the age of the standard. It should be better than $\sim 5 \%$.

For volcanic, hypovolcanic rocks, and shallow intrusives, the FT method dates the time of formation, provided they were not further reheated. More generally, the track method provides cooling ages. Closing temperatures calculated from laboratory experiments vary from $\lesssim 300^{\circ} \mathrm{C}$ to $100^{\circ} \mathrm{C}$, according to minerals, for slow cooling rates $\left(\sim 1^{\circ} \mathrm{C} / \mathrm{m} . y\right.$.). For apatites, recent geological calibrations (Néteser et al 1980 ; Gleadow and Duddy 1980) confirmed laboratory extrapolations. The association of the FT method with other geochronometers is therefore critical to the study of the cooling history of old cratons as well as to the evaluation of uplift/erosion. rates in recent belts.

Keywords. Fisșion tracks; fission track dating; track annealing; fission decay constant; neutron dosimetry; model ages; plateau ages; cooling and uplift rates.

\section{Introduction}

The fission track (FT) method of dating proposed in 1963 by Price and Walker has been shown to apply to a variety of problems from anthropology to plate tectonics and cosmochronology (Fleischer et al 1975). Methods have been devised in order to take into account in age determinations the effect of partial fading of fossil tracks (Storzer and Wagner 1969; Storzer and Poupeau 1973a). However, the FT ages reported in the literature are too often difficult to use and compare with other radiometric

*Paper presented at the second national seminar-cun-workshop on the use and application of solid state nuclear track detectors held at Physical Research Laboratory, Ahmedabad, India, during 24-26 February 1981. 
methods, either because their quoted precision is unclear or due to uncertain choices of parameters in the equation used for deriving FT ages.

There is an urgent need of standardization in FT dating; specifically, it should include both the use of recognized standards for interlaboratory calibrations and the adoption of widely accepted models for evaluating the precision of the measured ages. It is the aim of this paper to give the present status of FT dating from the point of view of precision, accuracy, and meaning of ages. Model ages will be specially considered. In this context, we present here the first set of analytical data obtained in minerals by plateau methods of dating (preliminary accounts were given in Poupeau et al 1978a, b; 1980a, b, and Carpena et al 1980). Recent general accounts of the FT dating method can be found in Naeser $(1978,1979)$, Wagner (1978, 1979), Poupeau (1981a), and Poupeau and Rajan (1981).

\section{Relevant relationships}

Any FT age $t$ is obtained basically by counting two track densities (expressed as number of tracks per unit area), respectively, the densities $D_{f}$ of fossil tracks from the spontaneous fission of ${ }^{238} \mathrm{U}$ and $D_{i}$ from ${ }^{235} \mathrm{U}$ induced fission tracks, the latter ones produced by irradiation of the sample by thermal neutrons in a nuclear reactor. In order to discuss the precision and meaning of an FT age, it is convenient to write the age equation (Price and Walker 1963) in the form" (Poupeau et al 1980b):

$$
t=A \ln \left\{1+B \frac{\eta^{235}}{\eta^{238}} \frac{D_{f}}{D_{i}}\right\}
$$

where $A=1 / \lambda_{t}$ and $\lambda_{t}=1.55125 \times 10^{-10} \mathrm{yrs}^{-1}$ total decay constant of ${ }^{238} \mathrm{U}$ (Jaffey et al 1971),

$$
B=\frac{\sigma I \phi \lambda_{t}}{\lambda_{f}} \frac{\bar{R}^{235}}{\bar{R}^{238}}, \text { with }
$$

$\sigma=580$ barns (Table of isotopes, 1978), cross-section of ${ }^{235} \mathrm{U}$ fission by thermal neutrons,

$l=7.235 \times 10^{-3}$ (Cowan and Adler 1976), natural ${ }^{235} \mathrm{U} /{ }^{238} \mathrm{U}$ isotopic ratio,

$\phi=$ thermal neutron dose (neutrons $\mathrm{cm}^{-2}$ ),

$\lambda_{f}={ }^{238} \mathrm{U}$ spontaneous fission decay constant. Two values of $\lambda_{f}$ are principally in use (see $\S 6$ ): $\lambda_{f}=7.03 \times 10^{-17} \mathrm{yrs}^{-1}$ and $\lambda_{f}=8.46 \times 10^{-17} \mathrm{yrs}^{-1}$,

$\bar{R}^{235} / \bar{R}^{238}=$ mean track length ratio of thermally unaffected fossil and induced fission tracks. From theoretical calculations (see Bhandari et al 1971) as well as experimental evidences, this ratio is taken as equal to one, and $B$ simplifies to:

$$
B=\sigma I \phi \lambda_{t} / \lambda_{f}
$$

*This form holds for the internal method of dating ( $\$ 3$ and figure 1). In the external detector geometry, $D_{i}$ would have to be replaced usually by $2 D_{i}$ (see Gleadow and Lovering 1977). 
nd $\eta^{238}=$ registration efficiency factors. They are measures of the fraction of tracks intersecting the external surface of a solid state track detector (SSTD) that can be made observable by chemical etching (Fleischer et al 1975).

practice, however, as one cannot measure directly the $\eta$ parameters, one always for FT age calculations, the following reduced form:

$$
t=A \ln \left\{1+B \frac{D_{f}}{D_{i}}\right\}
$$

b assumes $\eta^{235} / \eta^{238}=1 *$. This can lead to a meaningful FT age only when no al geological annealing affects the fossil tracks. This ideal situation occurs only aited circumstances, e.g. mineral dating of volcanic rocks and shallow intrusives. ${ }^{35} / \eta^{238}$ ratio higher than one is almost the rule in volcanic and impact glasses not infrequent in minerals from metamorphic rocks.

hen the fossil tracks are partially faded $\eta^{238}$ and thus $D_{f}$ are correlatively lowered, ge given by equation (2) is then an apparent age without geological significance peau 1981a, Wagner 1979). Therefore, for each FT age measurement it is absoy necessary (i) to determine whether or not $D_{f}$ has been affected by environal conditions during the geologic time of track storage, and (ii) to quantitatively this effect into account to 'correct' the apparent age given by equation (2) $\S 2$ below).

le precision of an FT age obtained by equation (2) is given by (Johnson et al ):

$$
\frac{\sigma_{t}}{t}=C\left\{\left(\frac{\sigma_{f}}{D_{f}}\right)^{2}+\left(\frac{\sigma_{t}}{D_{t}}\right)^{2}+\left(\frac{\sigma_{\phi}}{\phi}\right)^{2}-2 r\left(\frac{\sigma_{f}}{D_{f}}\right)\left(\frac{\sigma_{i}}{D_{l}}\right)\right\}^{1 / 2},
$$

re $\sigma_{t}, \sigma_{f}, \sigma_{i}$, and $\sigma_{\phi}$ are the standard errors on $t, D_{f}, D_{l}$, and $\phi$ respectively, the correlation coefficient between $D_{f}$ and $D_{l}$

$$
C=\frac{A}{t}[1-\exp (-t / A)]
$$

practical purposes $C \approx 1$ if $t<10^{8}$ yrs. Equation (3), as expressed in percent irs, then reduces to:

$$
E_{t}=C\left(E_{f}^{2}+E_{l}^{2}+E_{\phi}^{2}-2 r E_{j} E_{l}\right)^{1 / 2}
$$

are the $E$ 's are the percent errors on $t, D_{f}, D_{l}$ and $\phi$. Estimates of $E_{t}$ are discussed ow considering the various methods of track dating.

Incidentally, this also assumes that the neutron dose used to produce $D_{i}$ has no effect on the $\mathrm{k}$ recording and etching properties of the dated phase. 


\section{Dating techniques}

As the calculations of $E_{t}$ are somewhat dependent on the way $D_{f}$ and $D_{i}$ are measured, it appears relevant to recall briefly the main techniques used for FT dating.

As shown in figure 1, two methods can be used, either the external detector (ED) or internal detector (ID) method. In the ID method, $D_{f}$ and $D_{l}$ are most often measured on different samples-either two fragments of the same crystal (figure 1A), as often done for micas (where large crystals are available), or on two different groups of crystals, as typically practised for apatites (figure 1B). The method is called the internal detector method, since the surfaces on which track counts are made are surfaces internal to the mineral. The internal surfaces are generated, prior to etching, either by fracturing along cleavage planes (micas) or polishing (other minerals and glasses). Alternatively (figure $1 \mathrm{C}$ ), both $D_{f}$ and $D_{l}$ can be counted on the same piece of mineral provided that a repolishing after neutron irradiation reveals a new internal surface. The thickness of the removed layer must be greater than, or equal to, the range of one fission fragment.

In the external detector method, the induced fission tracks are either etched on the same face as the fossil tracks (figure 1D) or on an external detector placed against a polished surface of the sample to be dated during irradiation (figure 1E).

Whereas any procedure in principle can be applied to samples where the uranium distribution is uniform, procedures $1 \mathrm{C}$ to $1 \mathrm{E}$ are more appropriate to those samples where the $U$ distribution is irregular on a small scale.

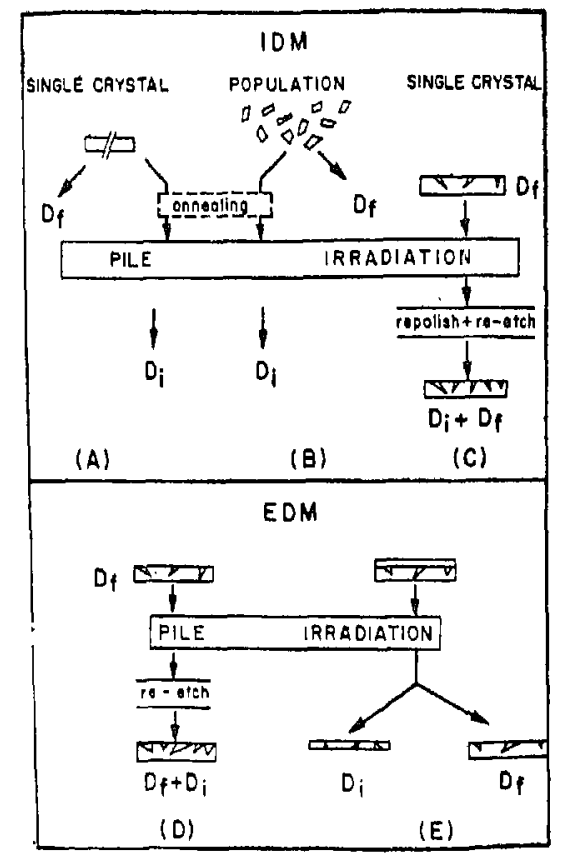

Figure 1. Fission track dating methods (see text), IDM and EDM, respectively, refer to internal detector and external detector methods; $D_{f}$ and $D_{i}$, fossil and thermal neutron induced fission track densities. 


\section{Precision on apparent ages}

The precision on apparent age, i.e. an FT age directly derived from equation (1), depends primarily on the parameters $D_{f}, D_{i}, r$, and $\phi$.

\subsection{Precision on $\phi$}

The neutron dosimetry in $\mathrm{FT}$ dating is usually carried out by radioactive countings of metal monitor foils ( $\mathrm{Co}, \mathrm{Cu}, \mathrm{Au}$, etc.) or by irradiating a uranium glass standard simultaneously with the sample and then counting the induced fission tracks produced in the standard. These standards are usually intercalibrated to metal foils (Carpenter and Reimer 1974).

With metal foils, a statistical precision of $1 \%(2 \sigma)$ can be achieved without difficulty, With uranium glass standards, a precision of the order of $4 \%(20)$ can be reached if about 2,500 fission tracks are counted.

\subsection{Precision on $D_{f}, D_{l}, r$ and the apparent age $t$}

The precision of $D_{f}$ and $D_{i}$ is usually calculated from poisson or gaussian statistics. Since the uranium distribution in samples is often not perfectly homogeneous, the latter statistical approach generally is considered to give a more realistic evaluation of the uncertainty in track counting (Naeser 1978). However, regrettably, no justification (statistical test results) for the choice of a particular statistics is given in the published literature on FT dating. Often the use of a poissonian law results in a lowering of the counting uncertainty estimates.

The evaluation of the correlation coefficient $r$ of equations (3) and (5) is easy only in the $E D$ method when several minerals from a given rock are dated separately. It is suggested (McGee and Johnson 1979) that, in order to avoid the high sensitivity of $r$ with the number of measurements if only a few samples are used, at least 10 different samples must be analysed to calculate an FT age with this method. With the ED procedure (E) in figure 1, a precision on the apparent age $t$ of the order of $\pm 4 \%$ (2o) can be achieved (figure 2).

In the ID method, where the correlation coefficient cannot be calculated numerically, McGee and Johnson (1979) suggest to adopt a value of 0.8 as a "conservative guess.' In these conditions, assuming $E_{f}=E_{i}=E_{\phi}=2 \%(10)$, a precision of $\pm 5 \%(2 \sigma)$ can be obtained for the dating procedures $(A)$ and $(B)$ of figure 1.

When the induced tracks are measured on a sample where the fossil tracks were not thermally annealed before neutron irradiation, the net track density $D_{1}$ is deduced from the total track density $D^{*}$ after irradiation by:

$$
D_{i}=D^{*}-D_{f} .
$$

In this case, the precision on $D_{i}$ given by

$$
\sigma_{\left(D_{l}\right)}^{2}=\sigma_{\left(D_{f}\right)}^{2}+\sigma_{\left(D^{*}\right)}^{2}
$$

is larger than the statistical counting error. 


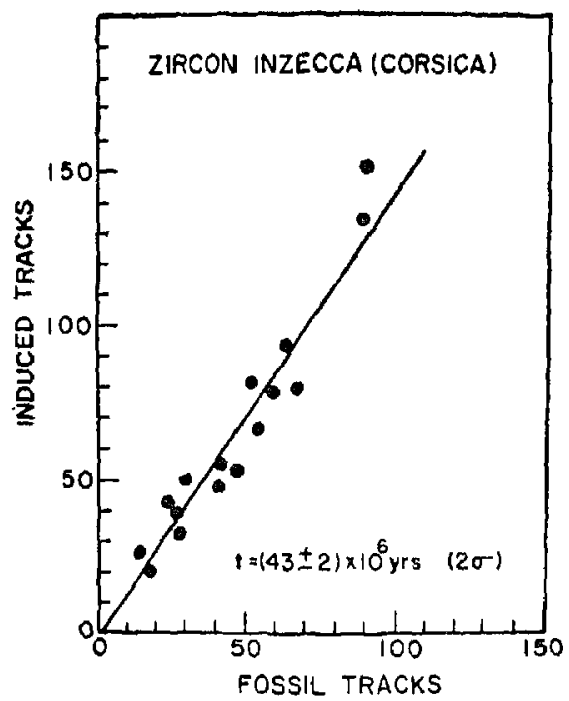

Figure 2. Isochrone age of 16 zircons from a trondjhemite (Corsica) dated by the external detector method. $E_{f}=3.66 \% ; E_{i}=3.13 \% ; \sigma_{\phi}=2 \% ; r=0.96$ (all errors are $1 \sigma$; from Carpena et al 1979). The numbers on axis are the number of fossil.and induced tracks counted per crystal.

The determination of errors on apparent ages, derived as discussed above, deals only with random error measurements. This approach does not take into account other sources of errors in the age such as counting geometry, adequacy of statistical laws applied to measured track distribution to calculate statistical counting errors, identification of tracks, actual value of the correlation coefficient $r$ (in the ID method), etc. The effect of track annealing and choice of constants are considered in the next two sections.

\section{Precision on model FT ages}

When fossil tracks are partially annealed, the ratio $\eta^{235} / \eta^{238}$ of equation (1) is no longer equal to one and correspondingly the condition of applicability of equation (2) is no more fulfilled. Therefore, a meaningful Fr age cannot be derived directly from this equation unless partial track annealing effect is taken into account. This can be done either by correcting the term $D_{f}$ of equation (2) for track density loss, in the 'track-size' correction method (Storzer and Wagner 1969), or by reducing the ratio $\eta^{235} / \eta^{238}$ to unity by a series of laboratory annealing steps in the 'plateau, method (Storzer and Poupeau 1973a). These two methods are based on the assumption that although partial track annealing results in a lowering of the etchable track density, it does not affect significantly-at least for fossil track density reduction* of $\lesssim 50-70 \%$-the volumic density (i.e. the number of etchable fission events per volume unit) of fossil tracks.

*As estimated from the literature [cf. for glasses Storzer (1970a) and minerals (biotite) Nagpaul et ol (1974)]. 


\subsection{FT ages corrected using the 'track-size' method}

5.1 a The model. The track-size method of correcting apparent FT ages is based on the observation that, with increasing degree of annealing, both the density of etchable tracks and their diameter (for glasses, where tracks present a characteristic ellipsoid etch pit shape) or length (in minerals) decrease (see Storzer and Wagner 1969).

In order to correct an apparent FT age by this method, one first has to establish from a series of thermal annealing experiments a calibration curve between the fractional reduction of the etchable track length and track density of thermal neutron induced ${ }^{235} \mathrm{U}$ fission tracks. Then, from the measurement of the ratio $\bar{L}^{238} \sqrt[\bar{R}^{235}]{ }$ (figure 3 ), one can graphically deduce the value of the correction factor $X$ to $D_{s}$. The corrected value of the fossil track density to be incorporated in equation (2) is:

$$
D_{f}(\text { corrected })=\frac{\left.D_{f} \text { (measured }\right)}{X} \times 100 .
$$

The introduction of the factor $X$ in equation (2), with its large associated uncertainty, will ultimately control the precision on the corrected age.

$5.1 b$ Precision on corrected FT ages. Although the 'track-size' correction method was introduced as early as 1969 (Storzer and Wagner 1969) and systematically applied later on by several groups, it is not yet clear how the precision on corrected FT ages is calculated as no account of its derivation has yet been given. However, some tentative estimate can be drawn from published data.

The precision on any age corrected by the size method depends, in addition to the precision on $D_{f}, D_{l}$, and $\phi$, on the uncertainties on $X$, i.e. on the ratio $\bar{L}_{f} / \bar{R}^{235}$ and on the calibration curve (figure 3 ).

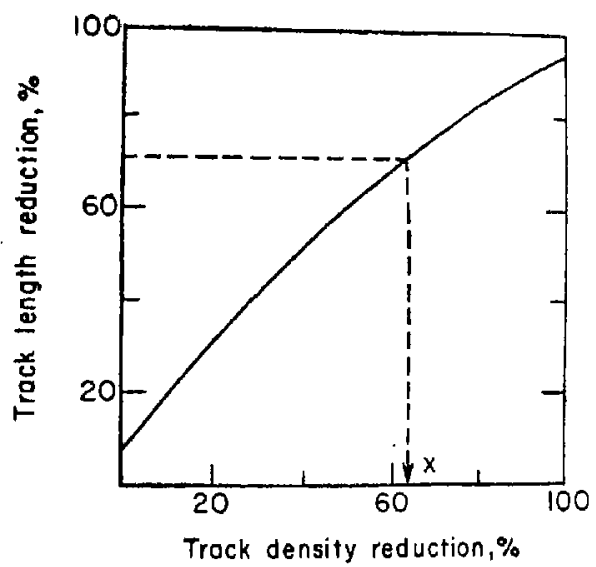

Figure 3. Correction of an apparent FT age with partially faded fossil tracks using the 'track-size' correction method. The ratio of the mean track length (or diameter, in glass) $\bar{L}_{f} / \bar{R}^{235}$ (see text) is used to deduce the percentage of track density loss. The corrected fossil track density is $D_{f}$ (corrected) $=100 / x D_{f}$ (measured). $\bar{R}_{f}$ and $\bar{R}^{23 s}$ are mean length of fossil and induced fission tracks, respectively. 
The mean track lengths (or diameter for glass) $\bar{L}_{f}$ and $\bar{R}^{235}$ seem to be usually calculated from only some 100 to 200 individual tracks (Storzer and Wagner 1969, Saini and Nagpaul 1979; Arias et al 1981). Moreover, it is seen from the track length/diameter distribution histograms published in the literature that, except for unannealed track length in minerals, as mcasured by the track-in-track method (Bhandari et al 1971), the distribution of track length or diameter does not generally follow a gaussian distribution. Therefore, the uncertainty on any mean track length is best taken as the standard deviation of the distribution (Saini and Nagpaul 1979):

$$
\sigma=\left(\frac{\Sigma\left(L_{f}-\bar{L}\right)^{2}}{n-1}\right)^{1 / 2}
$$

where $n$ is the total number of tracks measured, $L_{J}$ and $\bar{L}$, respectively, the length of the $j$ th track and the mean track length $\bar{L}=\Sigma L_{j} / n$.

The precision on the ratio $\bar{L}_{f} / \bar{R}^{235}$ is then given by:

$$
\sigma^{2}=\sigma_{\bar{L}_{f}}^{2}+\sigma_{\bar{R}^{235} .}^{2}
$$

Calculations of $\sigma_{L_{f}}^{2}$ and $\sigma_{\bar{R}^{335}}^{2}$ from histograms reported in the literature show that, in general, the standard error $\sigma^{2}$ is of the order of $10 \%$. As a result, the error on $X$ is of about $15 \%$.

Assuming the error on the calibration curve as comparatively negligible, the precision on an FT age corrected by the track-size method can be derived using a modified form of equation (5):

$$
E_{t}^{2}=C\left(E_{f}^{2}+E_{i}^{2}+E_{\phi}^{2}+E_{x}^{2}-2 r E_{f} E_{t}\right) .
$$

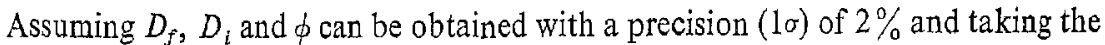
parameter $C$ of equation (3) as equal to one, it appears that whatever the value of $r$ (between 0 and 1) the precision on an FT age corrected with the track-size value cannot be better than $\sim 16 \%(1 \mathrm{c})$. This evaluation is of the same order as the one suggested in the initial article by Storzer and Wagner (1969).

The preceding discussion was based on the assumption that the fossil track length distribution was unimodal, which is generally the case. When bimodality is present, i.e. when two populations of fossil tracks show different degrees of fading (see Storzer 1970a; Nagpaul et al 1974), an additional error has to be taken into account, liuked to the demodulation of these two peaks, which date different events. The extent of this additional error could be of the order of 20\% (Storzer $1970 \mathrm{a}$ ).

Therefore, as useful as it may be, the size correction method does not allow a fine time resolution, as its overall precision $( \pm 2 \sigma)$ seems to be, at best, of the order of $\pm 30 \%$.

\subsection{FT ages corrected using the plateau method}

The major source of uncertainties in the track-size correction method comes from track length (or diameter) measurements. The pleateau methods are aimed at giving FT ages directly corrected for partial geological track fading. Since no detailed 
analytical data have yet been published, a few examples of plateau age dating of micas and apatites will be given below after a discussion of the precision of these methods.

5.2 a Principle and precision of plateau age dating. The plateau method represents in attempt to fulfill the condition $\eta^{235} / \eta^{238}=1$ of applicability of equation (2). In order to do so aliquots of the mineral phase to be dated, with latent fossil and incuced fission tracks, respectively, are annealed under various conditions (time, $\eta^{238}$, with the presuce $\eta^{235}$ to the same value as (the eventually geologically lowered) constant and will be have been proposed to achieve this goal: the ingling (figure 4). Two procedures (Storzer and Poupeau 1973a; Popeau et al 1980a) and the isotheau (ICP) method method (Dakowski et al 1974).

In each of these methods, a series of apparent FT ages is measured on aliquots

\section{ISOCHRONAL FT PLATEAU DATING}
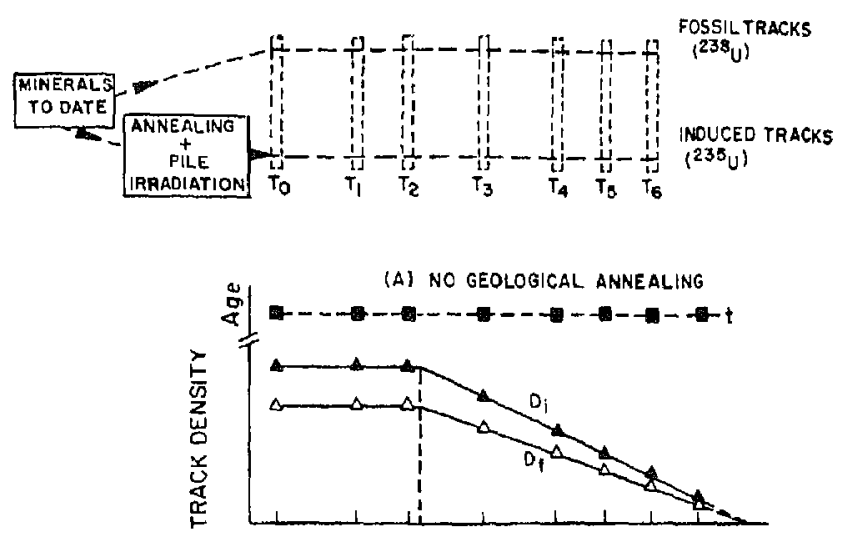

(B) PAFTIAL geOLOGical anNeaLing

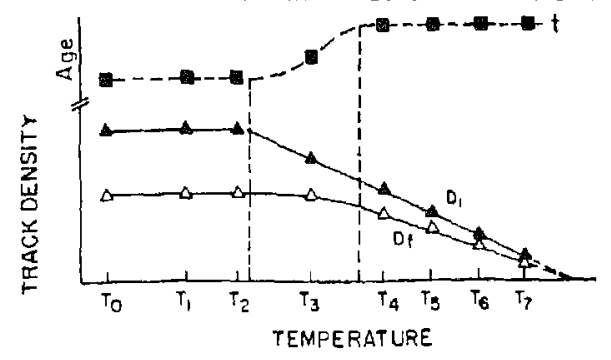

Figure 4. Principle of isochronal FT plateau age dating. The minerals to date are split into two sub-samples for the measure of fossil and induced fission tracks. Annealing is optional and to be avoided if suspected to modify the physical state of the dated mineral phase (f.i. glass). After irradiation, aliquots respectively with fossil and induced fission tracks are heated for a standard time at a given temperature and then dated. Depending on the absence or presence of geological annealing (figures A and $B$, respectively), different behaviour of the fossil track population is expected (Poupeau et al 1980a). 


\section{FISSION TRACK MODEL AGES}

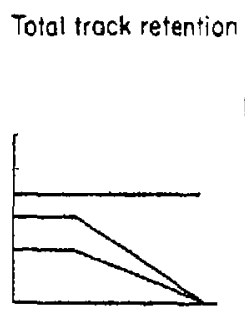

Partiol geological anneoling

ICP

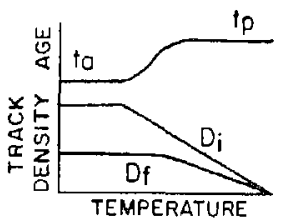

ITP
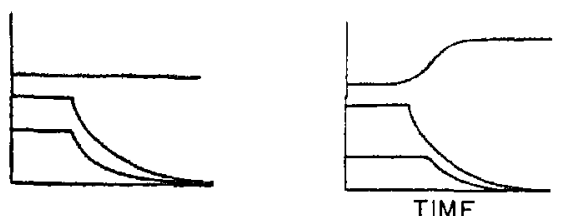

ISOCHRONE
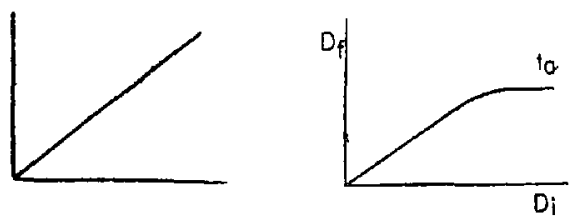

Figure 5. Comparison of the behaviour of $D_{f}, D_{t}$ and the apparent age $t$ with temperature in the isochronal plateau (ICP) method (top), or with time, in the isothermal platean (ITP) method (middle). With increasing temperature and/or time, $D_{f}$ and $D_{1}$ decrease; and their ratio (hence $t$ ) reaches eventually a constant value (isochrone representation of data, bottom figure). Eventually, if some geological anncaling affects the fossil tracks, the FT age will evolve from a low apparent age $t_{a}$ to a higher plateau value $t_{p}$. Scales in all diagrams are linear.

subjected to various thermal treatments before age measurements. In the ICP method (figure 4), the aliquots are submitted to annealing steps for a standard time (one hour in our routine procedure), each aliquot being dated after a single annealing step. In the ITP method, the aliquots are submitted to a cumulative series of annealing steps at a given temperature, but for increasing durations.

In the absence of geological fossil track fading, both $D_{f}$ and $D_{i}$ are supposed to react similarly to laboratory thermal treatment. Therefore, the ratio $D_{f} / D_{i}$ and, consequently, the FT age $t$ are expected to remain constant along the heating procedure (figures 4,5 ). On the contrary, if geological fading is present, $D_{f}$ will not be affected as much as $D_{t}$ in the first annealing steps (as fossil tracks are already partially annealed) up to a point where $\eta^{235}=\eta^{238}$; and beyond this point both track populations are expected to have similar annealing characteristics. Accordingly, the FT age $t$ would increase from a low value to a stable high temperature value. If several age measurements are made at the plateau, the final age $t_{\mathrm{pl}}$ and its precision $\sigma_{t_{\mathrm{pl}}}$ are calculated as weighted averages (Bevington 1969):

$$
t_{\mathrm{pl}}=\frac{\Sigma\left(t_{i} / \sigma_{i}^{2}\right)}{\Sigma\left(1 / \sigma_{i}^{2}\right)}
$$




$$
\sigma_{t \mathrm{pl}}^{2}=\frac{1}{\Sigma\left(1 / \sigma_{1}^{a}\right)}
$$

The errors $(2 \sigma)$ on plateau ages calculated from relations (10) are usually smaller than $\pm 5 \%$. Some illustrations are given below.

$5.2 b$ Examples of FT plateau ages. Although the applicability of the plateau method of Storzer and Poupeau (1973a) for minerals was questioned at first (Naeser and Fleischer 1975), it was later shown to give significant ages in micas and apatites from a variety of environments (Poupeau et al 1978a, b; Carpena et al 1979; Mailhe et al 1980). Typical examples of micas and apatites analysed by plateau methods are presented in tables 1 to 3 . Analytical data for three phlogopites and five apatites are given in tables 1 and 2, respectively; and plateau ages are compiled in table 3. The geological meaning of these ages was discussed elsewhere (Poupeau et al 1978a; Carpena et al 1980; Poupeau 1981b). All ages and their quoted precision have been recalculated (as in Poupeau 1981b) using (3) and (10). All minerals in tables 1 and 2 have been dated by the ICP method. In addition, two apatite samples (\# 2520 and Nages) have also been treated by the ITP method.

In micas, where uranium is homogeneously distributed, the errors on track densities were calculated as Poisson errors. From table 1, it appears that none of these micas has been affected by geological partial annealing: for each sample, the apparent age determined at ambient temperature is indistinguishable from those measured after some thermal treatment. As an expected consequence (see figure 5), annealing of both fossil and induced tracks start at about the same temperature in these micas as illustrated in figure 6 for the Ampandrandava and Mahanela samples. Similarly, in the is ochrone mode of representation (figure 7), no geological fading of the fossil tracks is discernible. In this case, plateau ages have been calculated (table 3 ) from all apparent age values giving a precision on the weighted ages of better than \pm $4 \%(2 \sigma)$.

In apatites, where uranium is generally less homogeneously distributed than in micas, the error on $D_{f}$ and $D_{i}$ has been evaluated with gaussian statistics rather than poissonian (Naeser 1978). The apatites were dated with the population method. Usually, track densities were measured from measurement on at least $\sim 40$ crystals, giving apparent ages with a precision of $\leqslant 10 \%$ and plateau ages of the order of \pm $5 \%(2 \sigma)$. In sample 70242 , where few crystals were available and track densities rather low (table 2 ), a precision on the plateau age of $\pm 9 \%(2 \sigma)$ was still achievable.

Two apatite samples (\# 2520 and M44), do not present any detectable geological annealing. Some annealing could be present in two others, M 34 and 70242, but the limited precision on the apparent ages of these samples prevents any definitive conclusion to be reached on this matter. Only the Nages apatites present a clear-cut case of geological track fading, with an apparent age of $197 \pm 14 \mathrm{~m}$. y., significantly lower than its ICP plateau value of $283 \pm 14 \mathrm{~m}$. y. (figure 8).

In principle, ICP and ITP treatments are supposed to produce similar results when applied to a given sample. This has been tested on the Nages and 2520 samples. On the Nages sample, both ICP and ITP ages were determined by the same observer. The plateau values of $283 \pm 14 \mathrm{~m} . \mathrm{y}$. and $281 \pm 22 \mathrm{~m}$.y. are in remarkable agreement. When all analytical data are combined together, they provide an age of $282 \pm 12 \mathrm{~m} . \mathrm{y}$. 


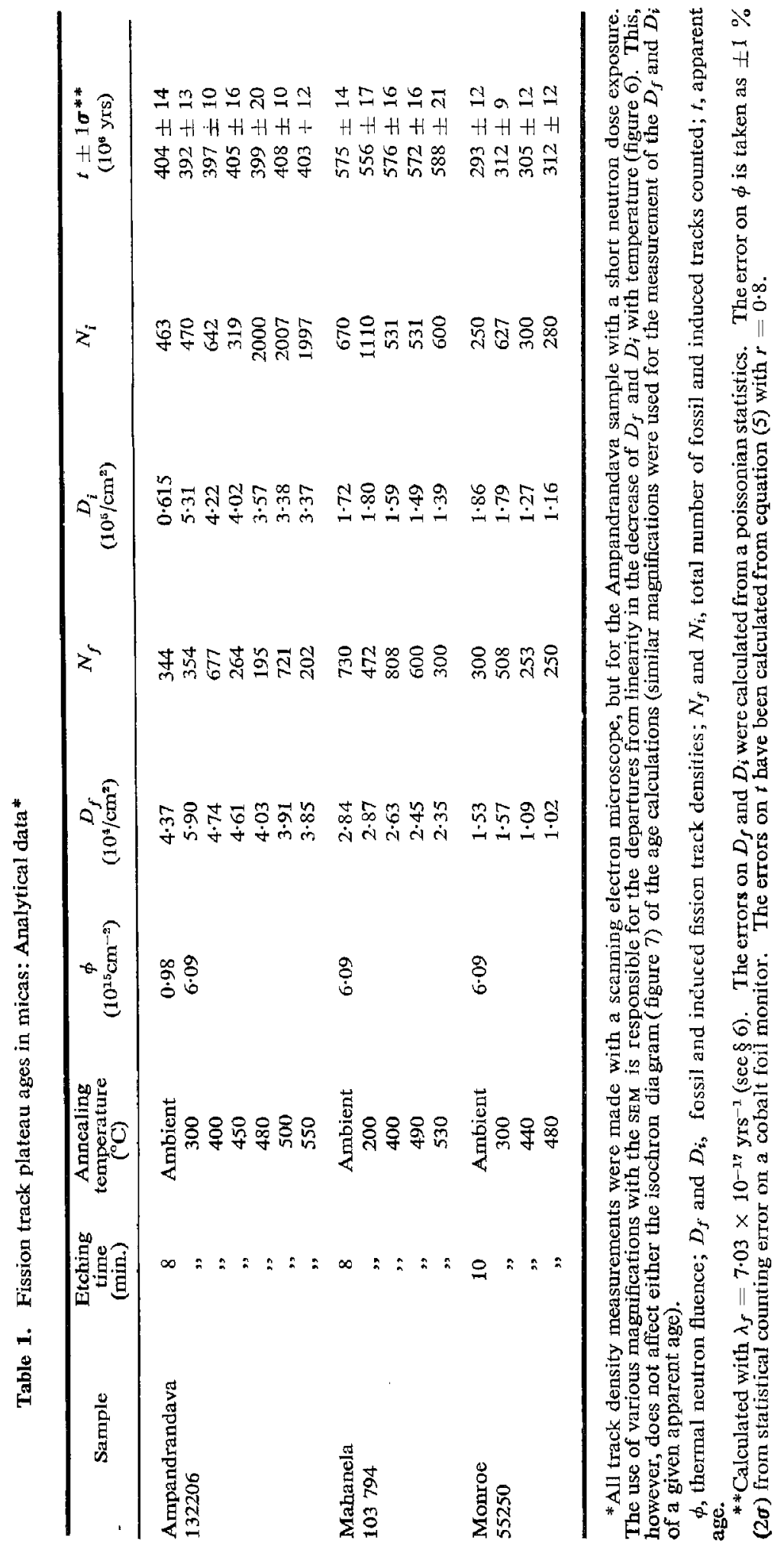




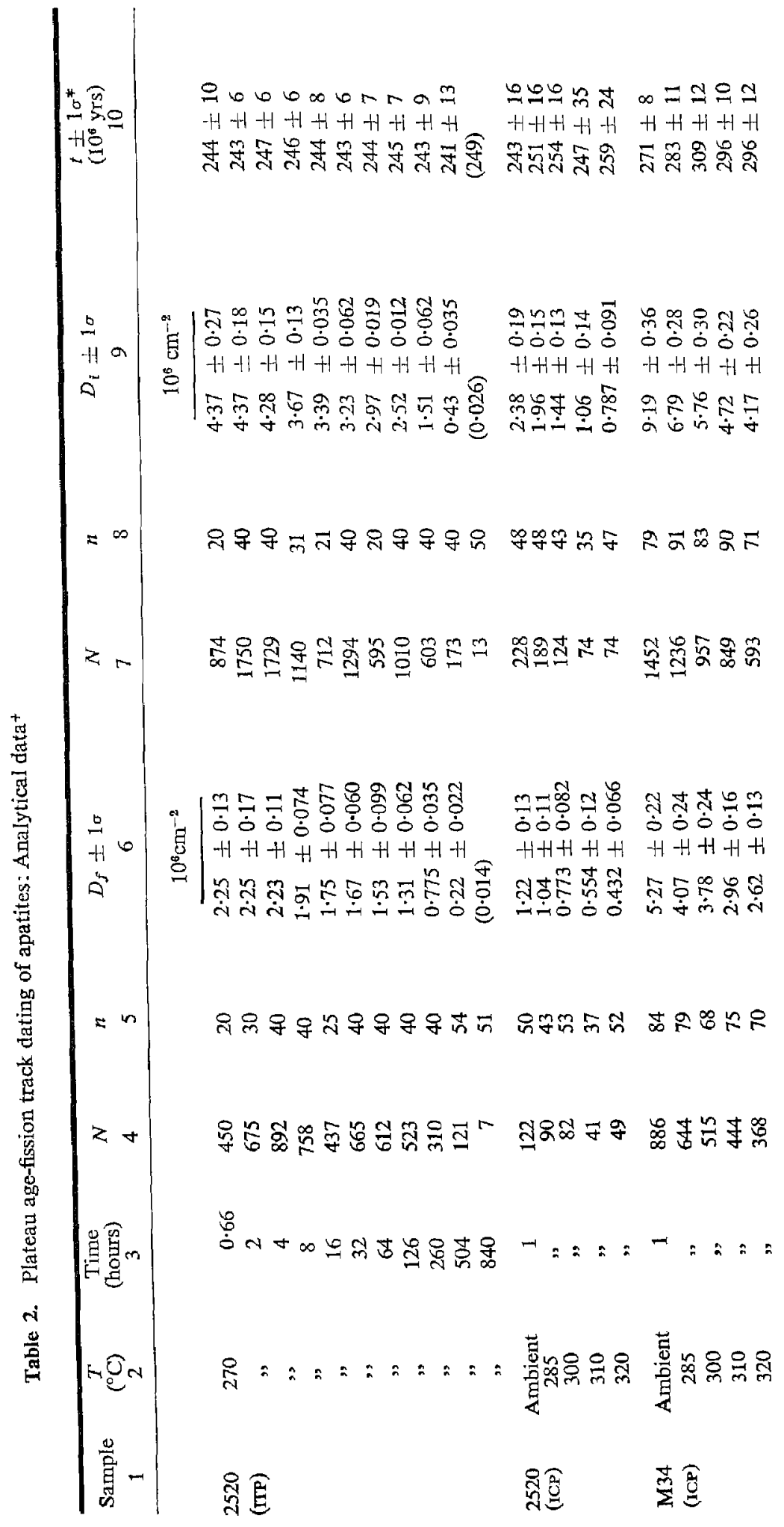




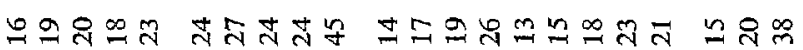
$H+H+H+H+H+H+H+H+H+H+H+H+1+H+H$

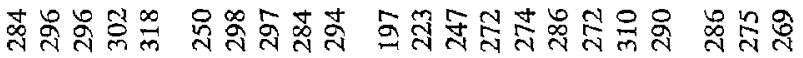

の

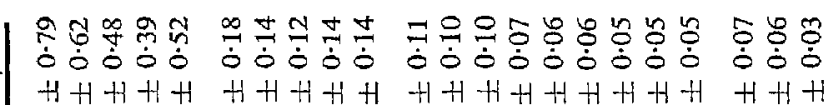

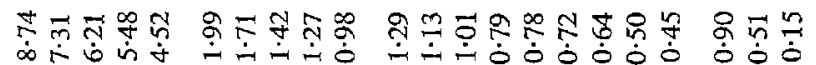

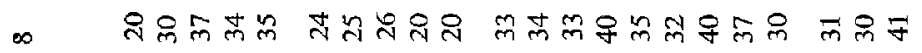

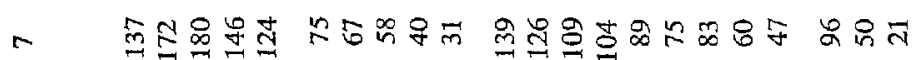

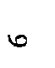

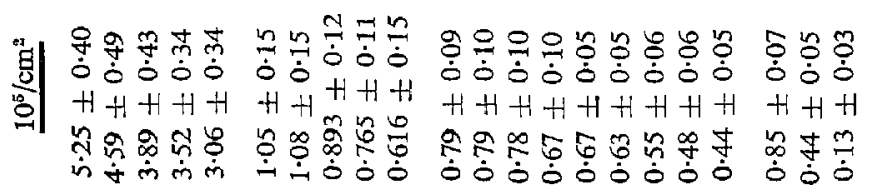

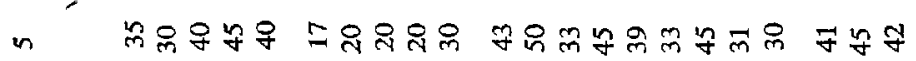

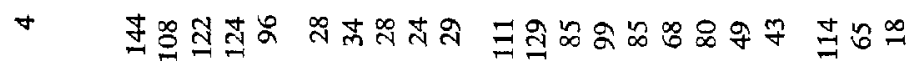

m

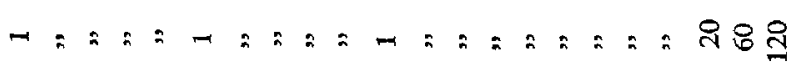

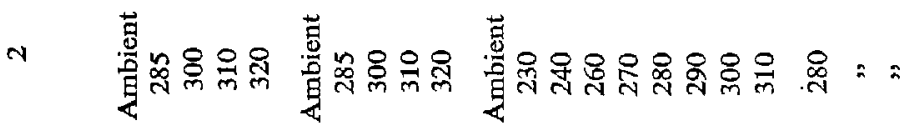

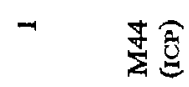
楚気 总

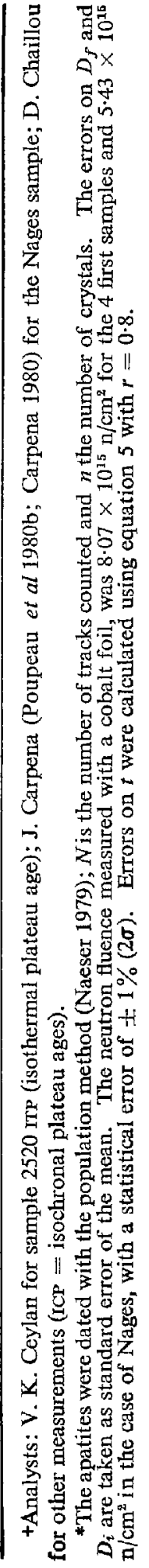


Table 3. Apparent and platcau ages of phlogopites and apatites ( $\left.\times 10^{6} \mathrm{yrs}\right)$

$\left.\begin{array}{lccc}\hline \multicolumn{1}{c}{\text { Sample }} & \text { 'Ambient' temperature age } & \multicolumn{2}{c}{\text { Plateau age }} \\ & (t \pm 2 \sigma) & N^{*} & t \pm 2 \sigma \\ \hline \text { Phlogopites } & & & \\ \text { Ampandrandova } & 404 \pm 28 & 7 & 401 \pm 10 \\ \text { Mahanela } & 575 \pm 28 & 5 & 572 \pm 14 \\ \text { Monroe } & 293 \pm 42 & 4 & 306 \pm 11 \\ \text { Apatites } & & & \\ \text { MOR 34 } & 271 \pm 16 & & \\ \text { MOR 44 } & 284 \pm 32 & 5 & 287 \pm 9 \\ 70242 & 250 \pm 48 & 5 & 296 \pm 17 \\ 2520 \text { (ICP) } & 243 \pm 32 & 4 & 292 \pm 27 \\ \text { 2520 (ITP) } & & 5 & 250 \pm 34 \\ \text { Nages (ICP) } & 197 \pm 28 & 10 & 244 \pm 5 \\ \text { Nages (ITP) } & - & 6 & 283 \pm 14 \\ & & 3 & 281 \pm 22\end{array}\right\} 282 \pm 12$

+The 'ambient' temperature age is the apparent age obtained without preannealing treatment (table 1). The plateau ages and their precision have been calculated from equation (11). In all cases except for sample 70242, the plateau ages were calculated from the apparent age mensurements (see text).

*No. of plateau steps.
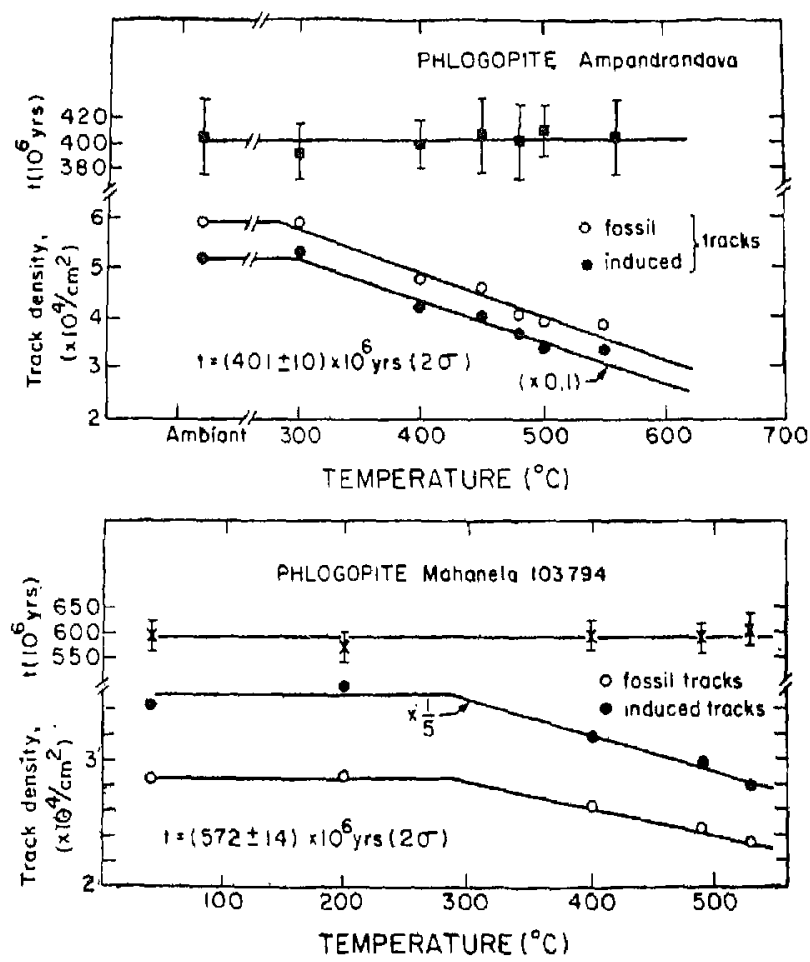

Figure 6. Isochronal plateau ages of the Ampandrandava (Malagasy) and Mahanela (Ceylon) phlogopites (see table 1). 

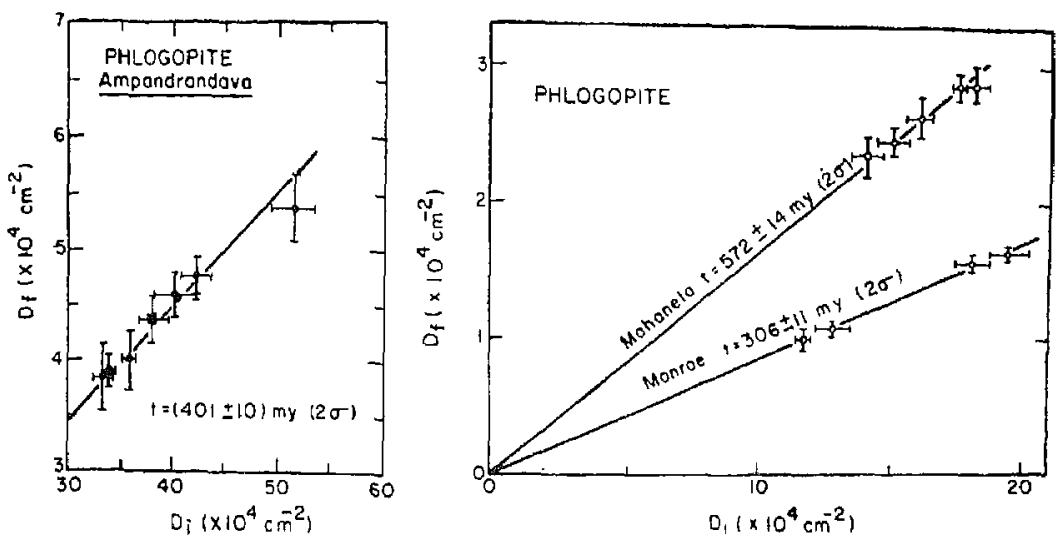

Figure 7. Isochrone representation of the phlogopite data from table 1. All track density measurements were made with a scanning electron microscope, except for one measurement of Ampandrandava sample (rectangle in figure); this last age was also determined with a neutron cose lower than for other measurements (table 1). The track densities have been normalized to a neutron fluence of $6.09 \times 10^{15} \mathrm{n} / \mathrm{cm}^{2}$.

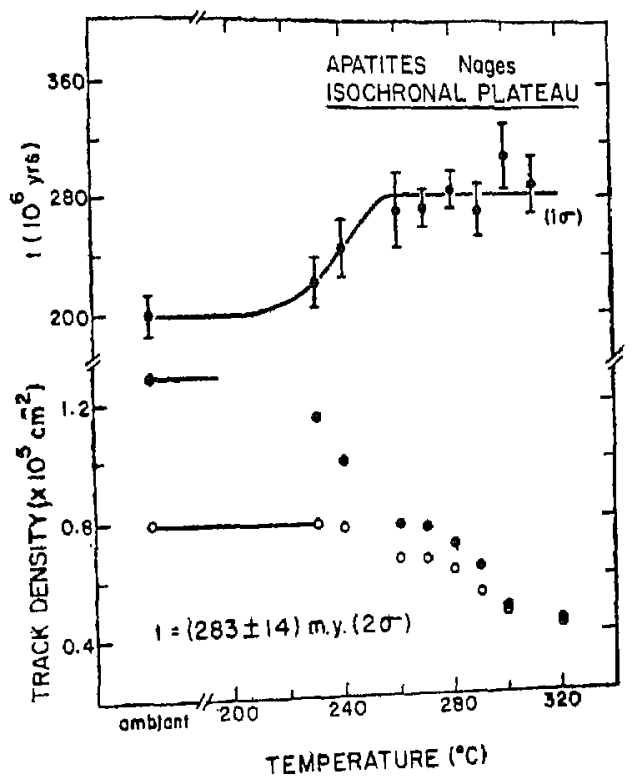

Figure 8. Isochronal plateau age of the Nages apatites.

(figure 9). Sample 2520 (figures 10 and 11) illustrates the effect of both the number of tracks counted and the number of apparent age determinations on the plateau age values. In this sample, the ICP and ITP data were obtained, respectively, by two different observers. Whereas the ages obtained by both of them are concordant, it appears that an effort on improving counting statistics (as in the ITP age determination of this sample) results in a much higher final precision. In particular, the effect of choosing a grid unit for countings, allowing a larger number of tracks per crystal to be counted, is to reduce considerably the scatter among individual determinations of $D_{f}$ and $D_{l}$ (figure 12). 


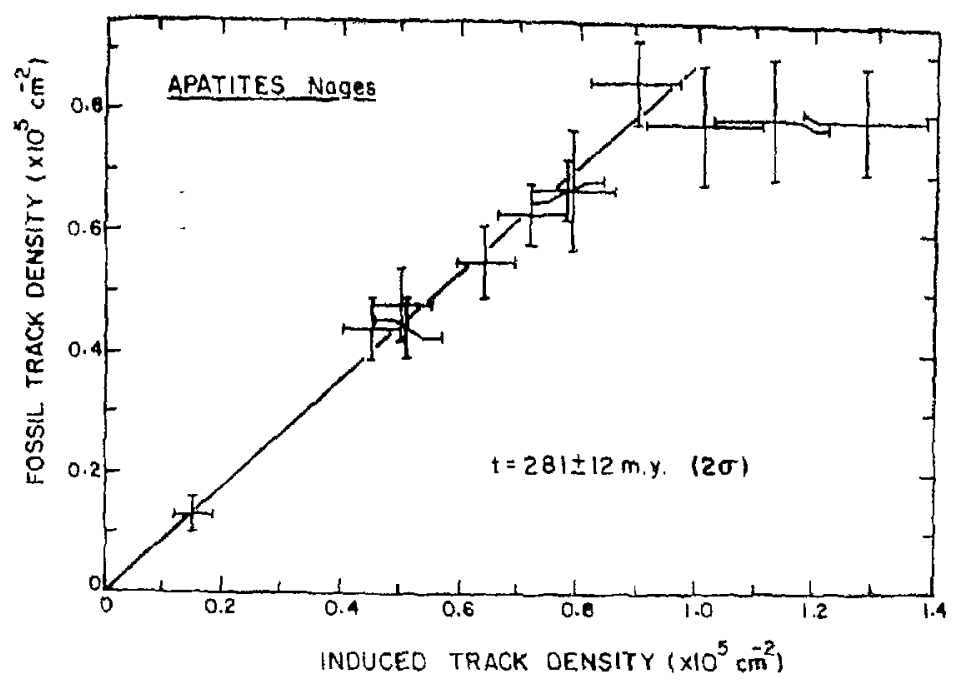

Figure 9. Isochrone representation of the ICP and ITP data for the Nages apatites.

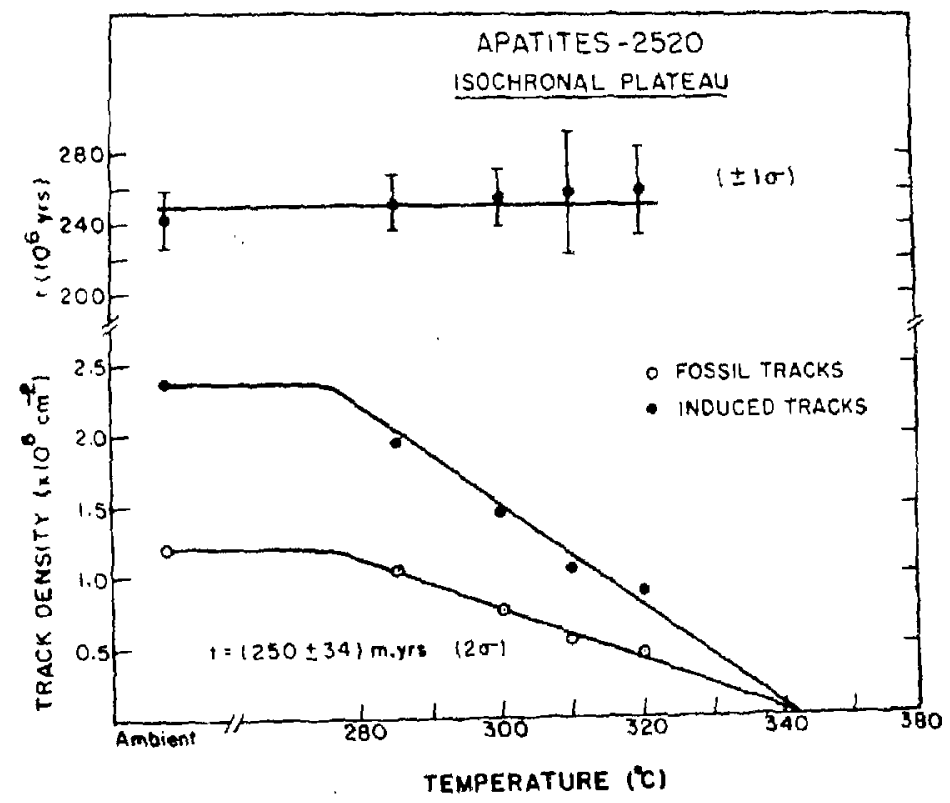

Figure 10. Isochronal plateau age of apatites 2520 .

Finally, as in the case of micas, it appears from tables 2 and 3 that a precision on apparent ages of the order of $\pm 5 \%$ to $\pm 10 \%(2 \sigma)$ results on a plateau value determined to within $\pm 5 \%(2 \sigma)$. It might be added here that the plateau age values of these apatites are in excellent agreement with the values expected from geological considerations (Carpena et al 1980; Poupeau 1981b).

The results in tables 1 and 2 having been obtained by the internal method of dating of the subtype $1 \mathrm{~A}$ of figure 1 for micas and $1 \mathrm{~B}$ for apatites, the correlation coefficient $r$ of equation (3) could not be calculated from the analytical data (McGee and Johnson 


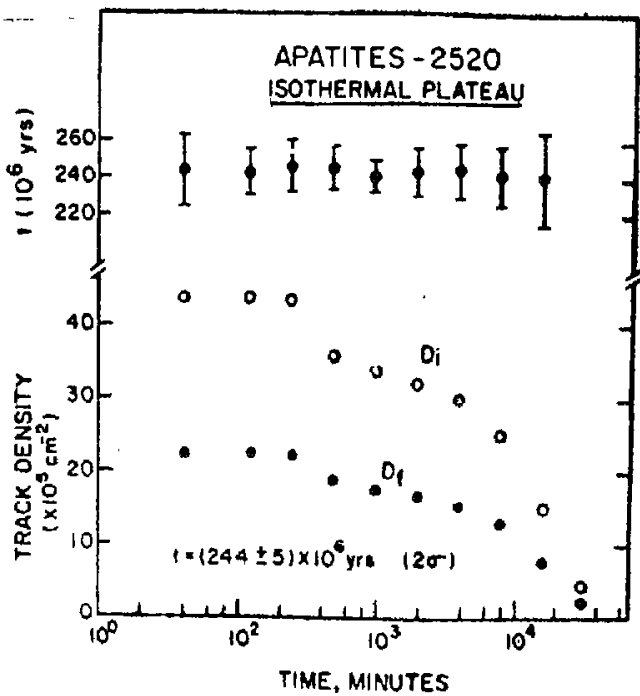

Figure 11. Isothermal plateau age of apatites 2520 .

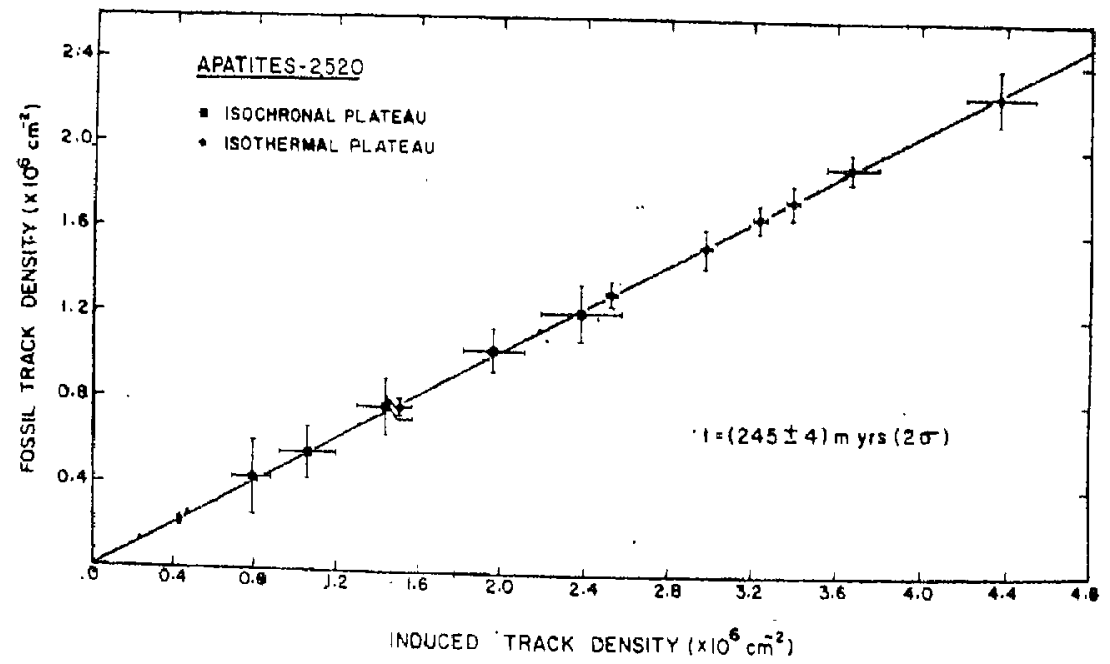

Figure 12. Isochrone representation of the ICP and ITP data for the 2520 apatites.

1979). As suggested by McGee and Johnson we have adopted in this case the 'conservative value' of $r=0.8$. A comparison (tables 1 and 2) between the errors calculated on individual ages and the dispersion of these ages for a given sample demonstrates a posteriori that an 0.8 value for the correlation coefficient between $D_{f}$ and $D_{l}$ gives, in effect, a conservative estimate of the precision on $t$ and, therefore, on the plateau ages themselves.

$5.2 c$ Remarks on the ITP method. Although equivalent from the point of view of plateau age precision, as seen above for apatites, the ICP and ITP methods cannot be indifferently applied to any mineral phase. For instance, thermal treatments at even moderate temperatures can modify the physical structure of certain mineral phases 

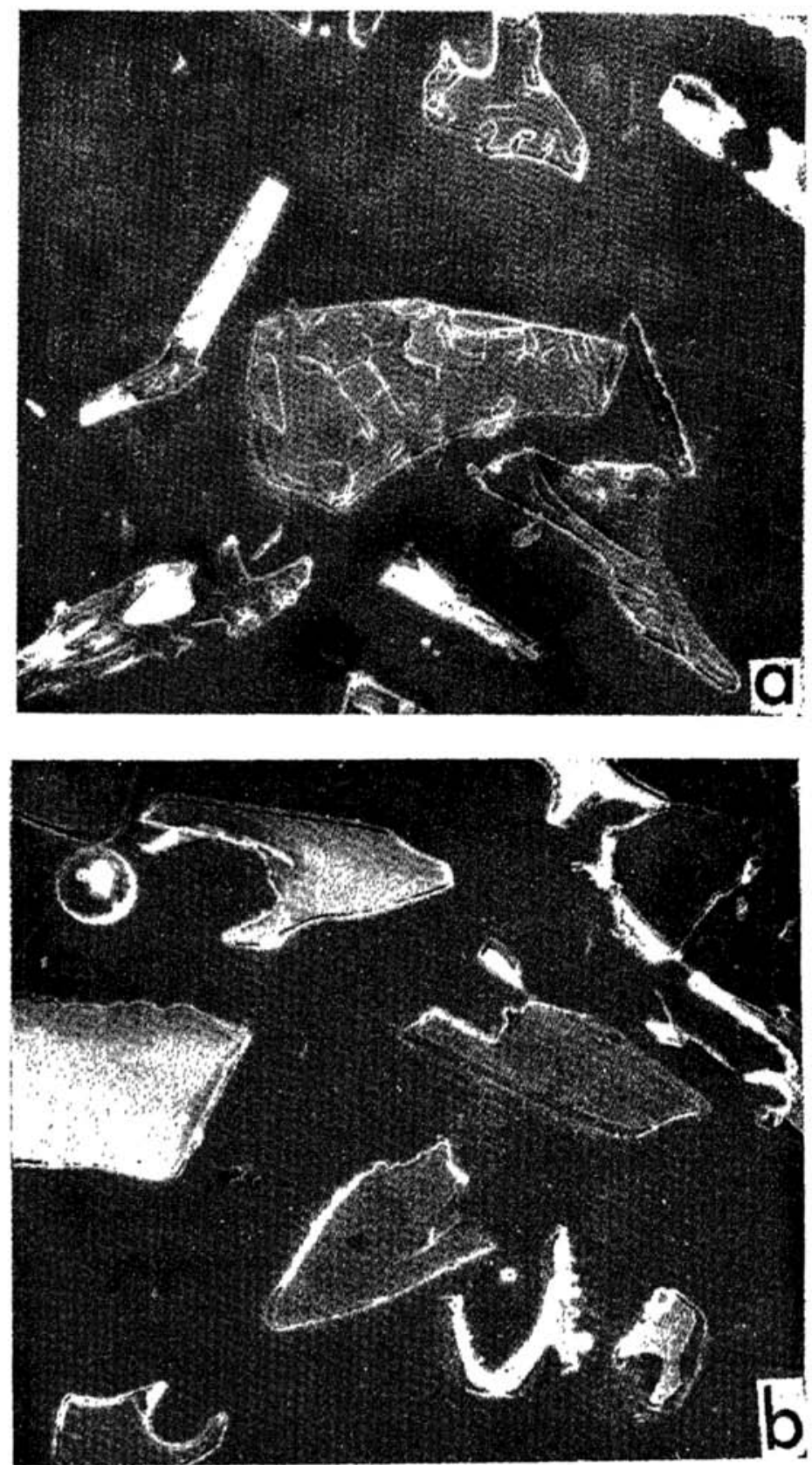

Figure 13. Effect of fission track etching ( $\mathrm{HF} 40 \% 20^{\circ} \mathrm{C}, 15$ seconds) on hydrated glass shards from the Middle Park tephra (Colorado). (a) Sample heated for $1 \mathrm{~h}$ at $220^{\circ} \mathrm{C}$ before etching, (b) unheated sample. Whereas in (b) the etching treatment does not affect the shards, all of those in (a) exhibit large etching figures. Scale bar, 100 microns. 

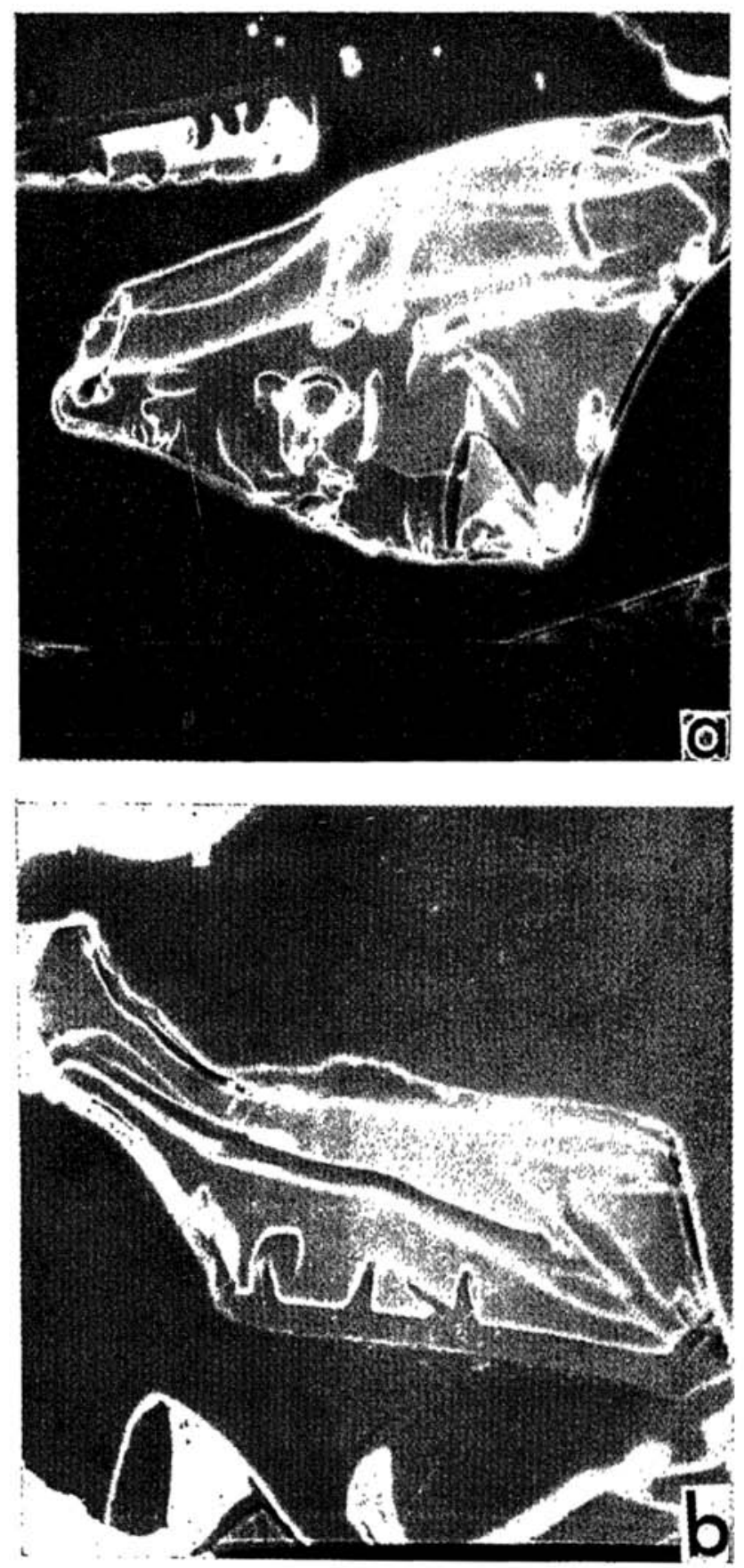

Figure 14, a and b 

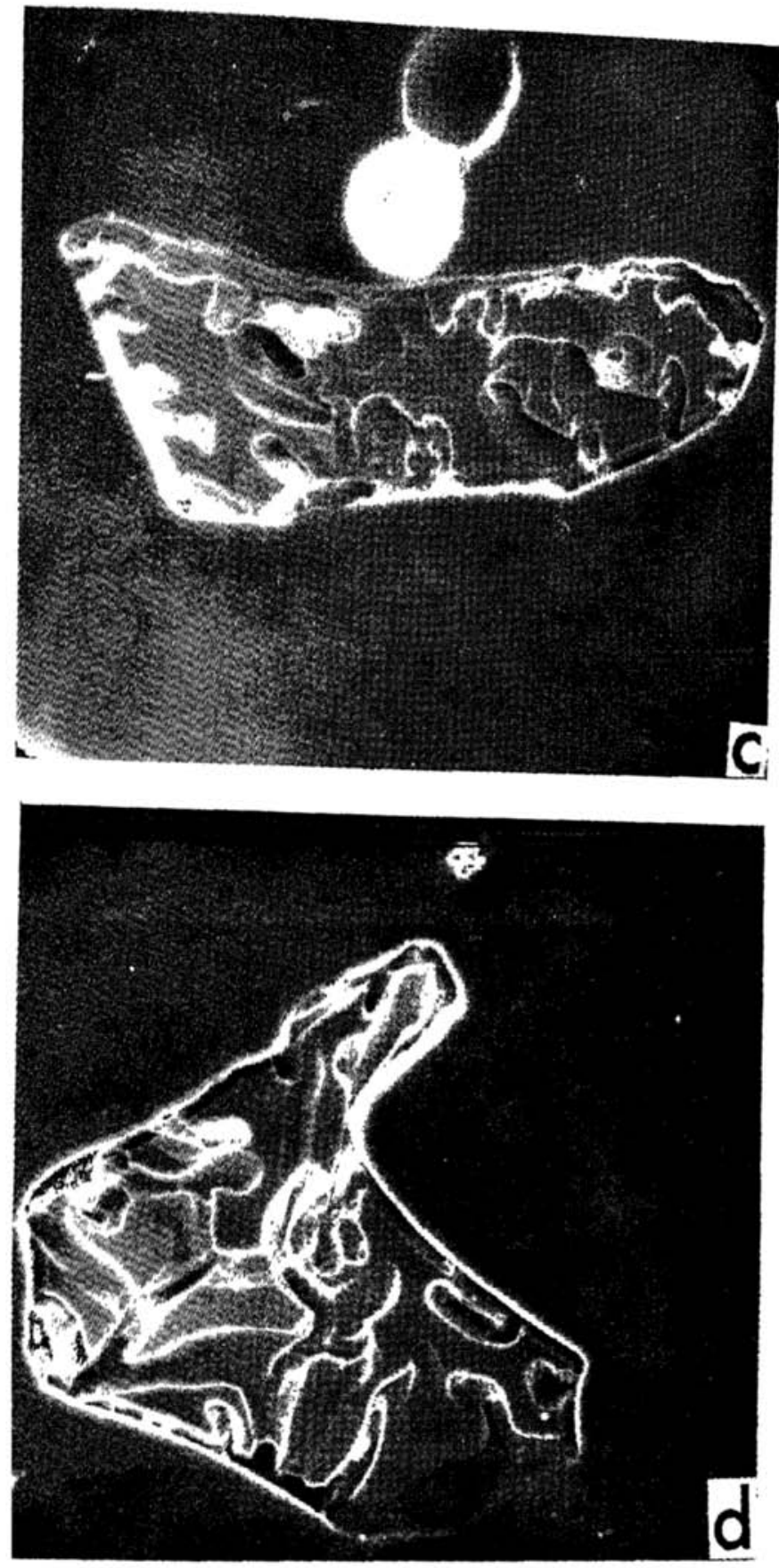

Figure 14. $c$ and d

Figure 14 Enlarged views of a few Middle Park tephra glass shards treated as in Figure 14. Enlarged views of a tew Midstl be counted on some parts of shards like (a) from figure 13. Fission tracks can still be counted on arge extent of etched corroin (a), (b), whereas it has become impossible due to the large extent of etched corto sion figures, as in (c), (d). Scal scanning electron microscopy). 
as in the case of metamict minerals (e.g. zircon) or volcanic glasses. For those phases, an ITP treatment is to be preferred, if not the only one possible. In order to illustrate these different properties of the ITP and ICP methods, we give below some data obtained on the FT dating of tephra glass shards.

Volcanic ash projections, or tephras, are very useful stratigraphic markers in sedimentary series. For instance, our knowledge of the timing of early hominoid evolution in the eastern African rift is basically obtained by the dating of tephra materials. The dating of these materials by the K-Ar or FT methods, especially for recent projections, is often extremely difficult (see Hay 1980) because of either (i) problems in $\mathrm{K}$-Ar dating, due to potassium leaching or contamination by crustal materials; or (ii) rarity of mineral phases convenient for FT dating, as zircons. Recently Naeser at al (1980) attempted FT dating of the main component of the tephras themselves, i.e., glass shards. The conclusion of these authors was that, although unhydrated glass shard dating was relevant with the plateau method, no reliable age could be obtained with altered (hydrated) glass shards due to some disruption upon track etching of these particles when submitted to thermal treatments above $\sim 200^{\circ} \mathrm{C}^{*}$.

Naeser and colleagues had been using an ICP method. Naeser kindly provided us with some of his samples on which we have been working with the ITp and ICP modes. We (Poupeau and Vincent, unpublished) effectively found that hydrated glass shards heated above $\sim 200^{\circ} \mathrm{C}$ reacted badly to track etching, as can be seen in figure 13: large channels and gulfs opened by etching are present in practically all shards from a heated $\left(1 \mathrm{~h}\right.$ at $\left.220^{\circ} \mathrm{C}\right)$ aliquot, whereas these are practically absent on the untreated sample. In figure 14, typical etch figures are displayed at higher magnification showing the details of shard behaviours. Samples from other localities may behave even worse.

In order to date the Middle Park shards of figures 13 and 14, the fossil tracks were not annealed. Our results, as well as those of Naeser et al (1979)are reported in table 4. The relatively limited damage caused by the corrosion figures of figures 13 and 14 still allowed, although painfully, to use the ICP method, for which we found-as for the 'ambient temperature' age-results in good agreement with those of the

Table 4. Apparent and plateau ages of the Middle Park tephra (Colorado) glass shards $\left(x 10^{\circ} \mathrm{yrs}\right)$

\begin{tabular}{rcccc}
\hline $\begin{array}{c}\text { 'High' } \\
\text { 'Ambient' } \\
\text { agc }( \pm 2 \sigma)\end{array}$ & $\begin{array}{c}\text { Source } \\
\text { age }( \pm 2 \sigma)\end{array}$ & Other ages $\uparrow$ & Source \\
\hline $9.4 \pm 1.4$ & $14.5 \pm 4.2$ & (a) & $13.5 \pm 2.2$ & (a) \\
$10.0 \pm 1.7$ & $17 \cdot 1 \pm 2.05$ & (b) & $13.3 \pm 1.2$ & (a) \\
& $15.4 \pm 1.0$ & (c) & & \\
\hline
\end{tabular}

$\dagger$ †T ages for zircons.

(a) Naeser et al 1980. The 'high' temperature age has been measured on a sample heated for 1 hour at $290^{\circ} \mathrm{C}$.

(b) and (c) Poupeau and Vincent (unpub. data). Age (b) was obtained on a sample heated for hour at $220^{\circ} \mathrm{C}$; age (c) was calculated from three individual ages determined on samples heated

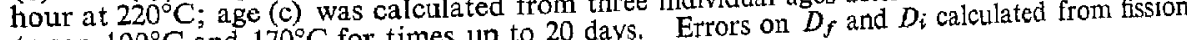
between $100^{\circ} \mathrm{C}$

*The disruption upon track etching of glassy shards was interpreted as a consequence of dehydration during thermal treatment. 
Denver group. However, we found that working in the ITP mode at $170^{\circ} \mathrm{C}$ allowed us to work comfortably without dealing with etch-damaged glass shards. Thus, we believe from these preliminary results that the ITP mode for the dating of tephra glass shards will ease in the future the use of this material for FT dating.

\section{Accuracy and standardization in FT dating}

The accuracy in FT dating is mainly controlled by the systematic errors on the ${ }^{238} \mathrm{U}$ spontaneous fission decay constant $\lambda_{f}$ and the neutron dosimetry. The other parameters in equation (1): $\lambda_{t}, I$ and $\sigma^{235}$ are known with an accuracy of better than $2 \%$.

\subsection{The $\lambda_{f}$ problem and thermal neutron dosimetry}

Since the discovery of the spontaneous fission of ${ }^{238} \mathrm{U}$ about 40 years ago, $\lambda_{f}$ has been determined more than 40 times (see compilation by Bigazzi 1981) ranging from 0.7 $\times 10^{-17} \mathrm{yrs}^{-1}$ to $28 \times 10^{-17} \mathrm{yrs}^{-1}$. Most values, however, are grouped in the interval $6.6 \times 10^{-17} \mathrm{yrs}^{-1}$ to $11.55 \times 10^{-17} \mathrm{yrs}^{-1}$, with two major peaks at $7 \times 10^{-17} \mathrm{yrs}^{-1}$ and $8.5 \times 10^{-17} \mathrm{yrs}^{-1}$, and a lesser one toward $11.7 \times 10^{-17} \mathrm{yrs}^{-1}$ (figure 15). Values of $\lambda_{j}$ determined by direct determination counters and radio-chemical or mass spectrometric analysis are evenly distributed in this interval. However, the values obtained by geological calibrations are strongly peaked around $7 \times 10^{-17} \mathrm{yrs}^{-1}$ and $8.5 \times 10^{-17}$ $\mathrm{yrs}^{-1}$, as do the determinations of $\lambda_{f}$ with nuclear emulsions or solid state track detectors when a thermal neutron irradiation in a nuclear reactor is performed. There is, therefore, some suggestion that neutron dosimetry might introduce a bias in the geological calibration of $\lambda_{f}$.

The thermal neutron dosimetry in FT dating is usually carried out either by the means of fission track counting in uranium-bearing glass standards, calibrated against

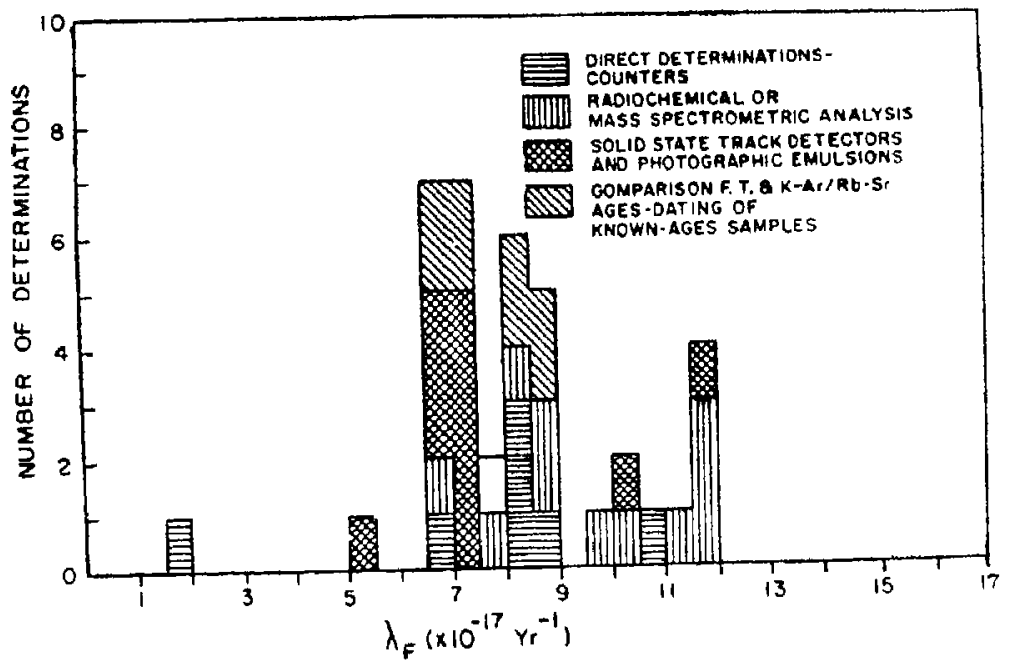

Figure 15. Histogram showing the distribution of $\lambda_{f}$ ( ${ }^{88} U$ spontaneous fission decay constant) as determined since 1950. A few earlier values in the range (22-28) $\times 10^{-17}$ yrs ${ }^{1-}$ have not been reported (courtsey, Bigazxi, 1981). 
metal foil monitors, or directly by measuring the activity induced in the metal foils. In the latter case, the thermal neutron flux $\phi_{\text {th }}$ is obtained from the total induced activity $A_{\text {tot }}$ as:

$$
\phi_{\text {th }}=\frac{A_{\text {th }}}{N \sigma_{m}}\left[1-\exp \left(-\lambda_{m} t\right)\right]^{-1}
$$

where $A_{\text {th }}=A_{\text {tot }}\left(1-1 / R_{c d}\right) ; \phi_{\text {th }}$ is the thermal neutron fluence $\left(\mathrm{n} . \mathrm{cm}^{-2}\right) ; A_{\text {th }}$, the thermal activity; $N$, the number of target atoms in the metal foil; $\sigma_{m}$ and $\lambda_{m}$ are, respectively, the thermal neutron capture cross-section for the target nuclide $\left(\mathrm{cm}^{-2}\right)$ and the decay constant of the daughter nuclide; $t$, the duration of irradiation; and $R_{c d}$ the cadmium ratio.

Therefore, given a well-dated geological sample (see below), $\lambda_{f}$ can be determined from* :

$$
\lambda_{f}=\frac{D_{f}}{D_{l}} \cdot \frac{\sigma I \phi_{\mathrm{th}}}{t},
$$

where $t$ is the age of the sample.

However, disappointing results were obtained following this approach for determination of $\lambda_{\rho}$. For instance, in two carefully designed experiments, Hurford and Gleadow (1977) and Wagner et al (1975) attempted to derive $\lambda_{f}$ from equation (12) using, respectively, minerals from volcanic rocks dated by $\mathrm{K}-\mathrm{Ar}$ and man-made glasses whose year of manufacture was known. From their measurements, the two groups were led to recommend for fission track work two different values of $\lambda_{f}$, differing from each other by as much as $20 \%$. Such a difference could not be explained either in terms of the uncertainty in the real ages of the samples selected or by partial track annealing of the fossil tracks (see, in particular, the further work of Naeser $e$ t al 1981, on some of the material studied by Hurford and Glendow). The two groups had used different methods of neutron dosimetry; and, as suggested by Hurford and Gleadow (1977) the differences in evaluation of $\lambda_{f}$ might be attributed to some ' unexplained systematic discrepancies' in the neutron dose measurements.

It may be stressed here how difficult it is to evaluate the proper thermal neutron fluence to the sample using metal foils. The accuracy of this neutron fluence depends not only on the parameters $\sigma_{m}$ and $\lambda_{m}$ (equation 11), but also on the particular shape of the neutron energy distribution at the place and time of irradiation in a given reactor, as the excitation functions of ${ }^{235} \mathrm{U}$ for neutron-induced fission and the monitor metal foil for neutron capture reactions have different neutron energy dependance.t

A large majority of FT-dating laboratories use glass standards for thermal neutron dosimetry. In this case, the thermal neutron fluence $\phi_{\text {th }}$ is deduced from the track

*This supposes also that the sample be irradiated in the reactor at a place where the ratio of thermal to epithermal neutrons is larger than 100 , so that the contribution of ${ }^{850} \mathrm{U}$-induced fission from epithermal neutrons is $<1 \%$ to that of thermal neutrons.

tOther factors include neutron flux spatial inhomogeneities; sample neutron self absorption, itself a function of chemistry and geometry of samples, all parameters not amenable easily to quantification. 
density $D_{\phi}$ in the glass*, or better, in an external detector fixed against it during irradiation, following the relationship

$$
\phi_{\text {th }}=K D_{\phi}
$$

In this case, any FT age is affected by an additional systematic error attached to the factor $K$ (this factor being determined through a joint irradiation of a metal monitor foil allowing the determination of $\phi_{\mathrm{th}}$ and the glass standard $t$ ).

Clearly, therefore, the situation about thermal neutron dosimetry is presently far from satisfactory, and improvements are urgently needed. Some suggestions in this direction are reported in $\S 6.3$. However, the examination of the present status of an interlaboratory comparison programme initiated by Naeser suggests that many FT laboratories have, through internal calbiration, reached the points where their data are geologically reliable.

\subsection{The Fish Canyon Tuff interlaboratory programme}

The Fish Canyon Tuff is a well-dated volcenic formation from Colorado. Its K-At age, as determined from sanidine, biotite, hornblende, and plagioclase (i.e. from mineral phases whose potassium content may differ by as much as more than one order of magnitude) is $27.9 \pm 0.7 \mathrm{~m}$. y. Naeser separated apatite and zircon crystals from an initial sample of $280 \mathrm{~kg}$ and distributed concentrates of these minerals to more than 50 laboratories, of which 19 reported data for apatites and 9 for zircons.

The main results of this programme (Naeser et al 1981) were to show that all laboratories using a $\lambda_{f}$ value near to $7 \times 10^{-17} \mathrm{yrs}^{-1}$ found apatite and zircon FT ages concordant with the K-Ar value, respectively, at $28.5 \pm 0.4 \mathrm{~m}$. y. (土 1 standard error of the mean) and $23.7 \pm 1.0 \mathrm{~m}$. y. On the other hand, the few laboratories using a $\lambda_{f}$ value $\sim 20 \%$ higher $\left(8.4 \times 10^{-17} \mathrm{yrs}^{-1}\right)$ found discordant ages of $24.7 \pm 1.0 \mathrm{~m}$. y. $\sim 20 \%$ lower than the $\mathrm{K}$-Ar ages, a difference not explainable in terms of fossil track annealing (Naeser et al 1981). This report unfortunately does not precisely describe the methods for neutron dosimetry used by each laboratory.

In May 1981, a new extensive sampling of the Fish Canyon Tuff has been made (Naeser, personal communication), and separated apatites and zircons will be made available through the National Bureau of Standards (Washington, D. C.). It would be worthwhile that, in this further step of interlaboratory comparisons on the Fish Canyon Tuff, data concerning the neutron dosimetry are provided by the participating groups and made available to the whole community.

\subsection{Toward a standardization in FT dating?}

From the preceding discussion, it results that neither the spontaneous fission decay constant $\lambda_{f}$ nor the thermal neutron dosimetry are accurately known or measured. However, as shown in many publications, and especially on the systematic study of

\footnotetext{
*The induced fission tracks in the glass itself may be subject to partial annealing during irradiation, especially for long duration irradiations.

$\dagger$ Moreover, there are indications that the factor $K$ itself may vary slightly with the reactor operating conditions (Hurford and Gleadow 1980; Carpenter, pers. comm. 1981).
} 
the Fish Canyon Tuff, significant FT ages can be obtained. This is due to the fact that in practice, according to its own method of neutron dosimetry, each laboratory defines an operational ' $\lambda_{\rho}$ ' value allowing to find the adequate 'age' for welldated geological standards.* Accordingly, the ultimate accuracy of any FT, age is limited by the accuracy on the age of the geological standard rock, i.e. about $3 \%$ with the Fish Canyon Tuff standard. In order to facilitate the problem of age intercomparisons between different laboratories, several standards were proposed for neutron dosimetry (Fleischer et al 1975). The most widely used at present are the NBS glass standards series set up by Carpenter and Reimer (1974). The laboratories using these glasses, as can be judged from the literature and personal contacts, tend to favour a $\lambda_{f}$ value around $7 \times 10^{-17} \mathrm{yrs}^{-1}$; and the value of $7.03 \times 10^{-17} \mathrm{yrs}^{-1}$ given by Roberts et al (1968) is currently being adopted by an increasing number of groups (Naeser et al 1979; Hurford and Gleadow 1977; Poupeau et al 1978a; Virk and Koul 1977; Parshad et al 1979) as replacing the widely used older values of $6.85 \times 10^{-17} \mathrm{yrs}^{-1}$ and $6.9 \times 10^{-17} \mathrm{yrs}^{-1}$, determined earlier by Fleischer and Price (1964).

Another value, of $8.46 \times 10^{-17} \mathrm{yrs}^{-1}$ (Galliker et al 1970) has been adopted by a few groups (e.g. Wagner et al 1976). It is based on $\lambda_{f}$ determinations from U-rich man-made glasses of known ages (Wagner et al 1975; Thiel and Herr 1976) as well as on geological calibrations with $\mathrm{K}$-Ar dated impact and volcanic glasses (Storzer 1970b; Storzer and Popeau 1973b).

Recently, Carpenter (1980) showed that, provided uranium isotopic composition and content in glass dosimeters are well known (which is the case of the NBs standards), the measure of the neutron fluence can be avoided. Still, an operational $\lambda_{f}$ value remains to be determined following the above lines.

The only way to eliminate the problems linked to $\lambda_{f}$ and $\phi$ would be (as in ${ }^{40} \mathrm{Ar}-{ }^{39} \mathrm{Ar}$ dating) to irradiate with each sample, $x$, to date, a geological sample of known age $t_{\mathrm{st}}$. The age equation then reduces to (Hurford and Green, 1980)

$$
t_{x}=\frac{1}{\lambda_{D}} \ln \left\{1+\lambda_{D} t_{\mathrm{st}} \frac{\left(\frac{D_{F}}{D_{l}}\right)_{x}}{\left(\frac{D_{F}}{D_{i}}\right)_{\mathrm{st}}}\right\}
$$

for which the percent error on $t_{x}$ would be given by a modified form of equation (5):

$$
E=C\left\{E_{f x}^{*}+E_{i x}^{2}+E_{f s t}^{2}+E_{i s t}^{2}-2 r\left(E_{f x} E_{i x}+E_{f s t} E_{i s t}\right)\right\}^{1 / 2} .
$$

The advantage of the two latter procedures would be that they avoid any systemam tic errors and eventual fluctuations in the factor $K$ of equation (13) without losing the precision of the dated phase.

*This assumes that both the FT method and the reference isotopic method date the same event. In recent volcanic rocks dated by $\mathrm{K}-\mathrm{Ar}$, this event is reasonably assumed to date the time of extrusion. 


\section{Meaning of FT ages}

An FT age dates the time since which the tracks are recorded in a mineral (Price and Walker 1963). Laboratory experiments have shown that even moderate temperature increases are able to reduce the etching efficiency factor $\eta$ to zero: one hour of heating between $50^{\circ} \mathrm{C}$ and $700^{\circ} \mathrm{C}$ (according to the mineral considered) is sufficient to completely erase fission tracks (Fleischer et al 1975). Extrapolation of laboratory thermal track annealing data (Arrhenius curves) have shown that in geological formations, fission tracks should not be recorded in minerals at temperatures above $\sim 300^{\circ} \mathrm{C} *$ (Fleischer et al 1975; Wagner 1979). As a consequence, FT ages can be interpreted as formation ages only for rocks with a very rapid cooling history**: volcanic and hypovolcanic rocks and eventually shallow intrusives. Thus, in most of the cases, FT ages should be considered as cooling ages, i.e. as dating the time since which the mineral cooled below a threshold temperature (temperature of track retention, or 'closing temperature', Dodson 1979). However, the interpretation of FT ages as cooling ages is also often complicated by the fact that, for a certain temperature range below the temperature $T_{0}$ at which fossil tracks start to be recorded (and, therefore, for a certain amount of time in the cooling history), the fission tracks are only partially recorded. This problem, which has been a source of confusion for years, deserves further comment.

\subsection{FT ages as cooling ages}

In order to discuss the meaning of $\mathrm{FT}$ ages as cooling ages, we have represented in figure 16 the evolution with time of the etchable track density in one mineral phase from a rock with differing cooling histories.

For a rock with a very rapid cooling (e.g. volcanic rocks) even the first tracks formed below the threshold temperature $T_{0}$ are fully recorded and have the same etch-

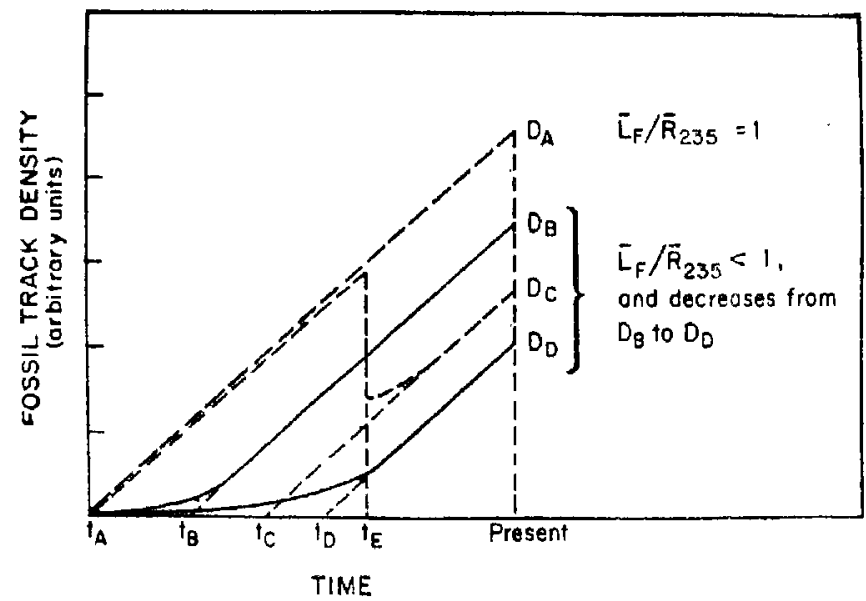

Figure 16. Evolution of the etchable fossil fission track density with time in a geo. logical sample with different cooling histories (see text).

*Quartz is a possible exception.

**As far as they have not been further reheated. 
ing efficiency as the recently formed tracks. In this case (if the time $t_{A}$ since which the rock cooled below $T_{0}$ is $<10^{8} \mathrm{yrs}$ ), $D_{f}$ increases linearly with time (Price and Walker 1963 ) to reach the present day value of $D_{A}$ (figure 16).

For rocks whose cooling rates below $T_{0}$ were 'slow,' the first tracks formed were only partially recorded and have an etching efficiency lower than the most recently formed track. This is reflected in figure 16 by the progressing increase of $D_{f}$ with time in the initial build-up of the etchable track density before reaching linearity. Depending on the cooling rate, the apparent ages measured from the etchable fossil track density can be considerably lower than the time of the beginning of track registration. For instance, the apparent fission track age for a sample having followed the $t_{A}-D_{B}$ path will be calculated at $t_{B}$; and with a still lower cooling rate, along $t_{B}-D_{D}$, the apparent age would even be much less $\left(t_{D}\right)$. Obviously the times $t_{A}, t_{B}$ and $t_{D}$ refer to different temperature histories.

Using Arrhenius plots for fission-track thermal annealing from the literature, Haack (1977) calculated the 'effective closing temperatures' corresponding to ages like $t_{B}$ and $t_{D}$, assuming different cooling rates. He showed that the closing temperature varies slowly with the cooling rate. For instance, in apatites, the calculated effective closing temperature changes from $95^{\circ} \mathrm{C}$ to $\sim 70^{\circ} \mathrm{C}$ for constant cooling rates between $10^{\circ} \mathrm{C} / \mathrm{m}$.y. and $0.1{ }^{\circ} \mathrm{C} / \mathrm{m}$.y. Similar results were reported by Dodson (1979).

However, if only the apparent ages are available, these results are of limited use to interpret fission track data. In effect, the cooling rate not only may have varied with time, but may also present discontinuities due to thermal pulses as in the path $t_{A}-D_{C}$ of figure 16 , where a thermal event at time $t_{E}$ may result in a meaningless apparent age, $t_{C}$.

It is these uncertainties in the meaning of any apparent age which led several authors to try to get model ages taking into account the partial geological track fading effects. The basic assumption of all model ages (" track-size' corrected ages or plateau ages) is that partial track fading affects only the etchable track density, but not the volumic (number per volume unit) density of recorded events. In other words, whatever the degree of partial fading in a sample, i.e. whatever may be the present-day etchable fossil track density between $D_{A}$ and less than $D_{D}$ in figure 16 , it should be possible to date with model-ages the time $t_{A}$ since which fossil tracks started to be recorded. Model ages, therefore, would refer to the time of beginning of track retention.

The track retention temperatures can be obtained from extrapolated laboratory annealing data (Arrhenius plots). One can, however, question if the extrapolation of annealing curves obtained from short duration laboratory experiments to times longer than $10^{8}$ yrs is valid. Recent geological calibrations (Naeser 1979; Naeser et al 1980; Gleadow and Duddy 1980) tend to lend some support in favour of this hypothesis. Taking advantage of favourable geological situations and samplings (f.i., geothermal drill holes), these authors were able to obtain a geological control of isothermal heating effects on fission track stability in apatites. For annealing times extending from $\sim 10^{8}$ yrs to $10^{8}$ yrs (figure 17), Naeser et al (1980) demonstrated that (i) the $50 \%$ geological annealing points for apatites, plot on the laboratory extrapolated curve; and (ii) the $100 \%$ and $0 \%$ annealing points plot, respectively, on $75 \%$ and $25 \%$ laboratory curves. In other terms, the range 


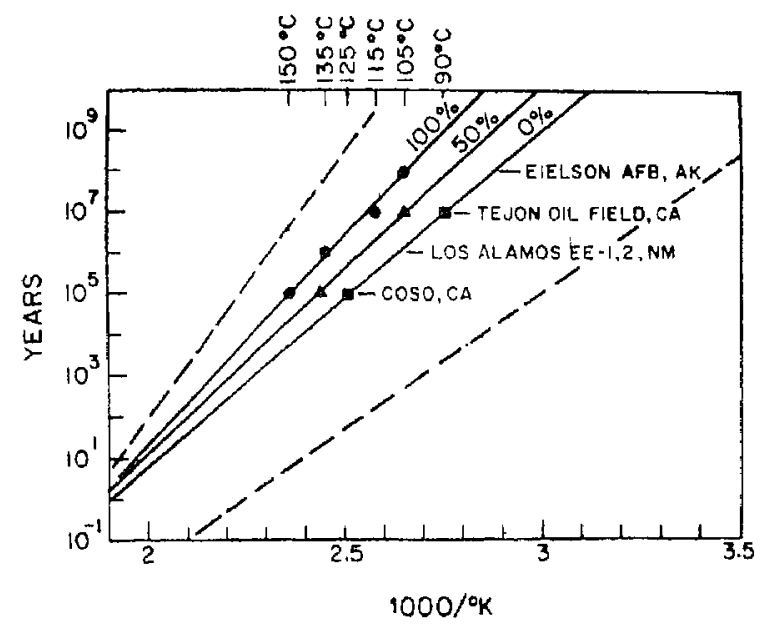

Figure 17. Arrhenius plots for the thrmal slability of tracks in apatites. Full lines, $0 \%, 50 \%$ and $100 \%$ track annealing curves as geologically calibrated from the fossil track record in four different apatite samples. Dotted lines, extrapolated laboratory Arrhenius annealing curves for $0 \%$ and $100 \%$ annealing. The $50 \%$ laboratory annealing curve coincides with the $50 \%$ geological calibration curve (courtesy, Naeser 1981).

of temperatures in which partial track retention would occur appears to be smaller than expected. These results are confirmed by those of Gleadow and Duddy (1980).

From figure 17 , it can be deduced from the $100 \%$ annealing plot that, in rapidly cooling basement rocks, the threshold temperature for apatites is of the order of $135^{\circ} \mathrm{C}$ (corresponding to $10^{8} \mathrm{yrs}$ isothermal annealing). For a rock with a model age of $10^{8}$ yrs, whatever its further cooling history, a direct reading of the $100 \%$ annealing curve indicates its closing temperature must be in the range $105-135^{\circ} \mathrm{C}$; the uncertainty in this range increases with increasing model age.

At present, apatites are the only mineral phase for which geological calibration of the closing temperature exists. Preliminary data exist for other phases as sphene and zircons, but they are yet too few to allow valuable comparisons with laboratory annealing data.

\subsection{FT ages and evaluation of uplift rates}

The concept of cooling age is by no means new in geochronology (see Faure 1979, and references therein); and it is well known that while some isotopic clocks start from the time of mineral crystallization or rock formation, others behave as closed systems for specific minerals below a certain 'closing' (or 'blocking') temperature upon cooling. Therefore, different isotope dating methods can, in principle, give an overview of the cooling history of a geological unit. It must be kept in mind, however, that this history will effectively describe a succession of thermal events with decreasing intensity. This may obviously be an oversimplification of the real thermal history of a rock, as sketched in figure 18. Discontinuities in the cooling history of a rock can thus be smoothed away by considering only the isotopic age distribution. Similarly, moderate thermal events can reset some geochronometers and, therefore, erase any memory of low temperature stages of the rock history, as shown for the case of apatites in figure 18. 


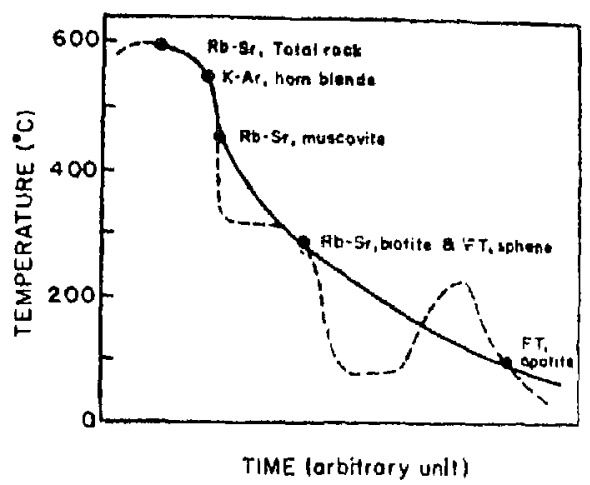

Figure 18. Hypothetical cooling history (dotted line) of a granitic body formed at $600^{\circ} \mathrm{C}$ and the smoothed cooling curve (solid Iine) that could be deduced from geochronological studies.

Certainly, the best way to define the past crystallization thermal history of a rock is to combine several geochronological approaches ( $\mathrm{K}-\mathrm{Ar}, \mathrm{Rb}-\mathrm{Sr}$, etc.) with the FT method. In doing this it must still be remembered that the geochemical 'closing temperatures ' are mostly meaningful for low cooling rates and that, at any rate, they are, whatever geochronometer is considered, generally slightly dependent on the cooling rate itself (Dodson 1979; Turner et al 1979).

With this limitation in mind, it is, however, possible to derive from any age difference $\Delta t$ between two geochronometers having a $\Delta T$ difference in closing temperature an uplift (or erosion) rate, following the equation (Sharma et al 1981):

$$
\text { uplift rate }=\frac{\text { cooling rate }}{\text { geothermal gradient }},
$$

where a (generally constant) value of the geothermal gradient has to be guessed. It is to be kept in mind that the ' uplift rate' so deduced depends only on the initial and final states of the system. This average value is not automatically representative of the actual cooling history. For instance, in many cases it is very difficult to decide whether or not the erosion (or uplift) was a continuous process with a constant rate in a given time interval $\Delta t$ (equation 16) or was mainly linked to tectonic pulses of short duration (figure 18). Moreover, differences of cooling ages between different minerals of a rock do not refer necessarily to any uplift. This may happen when the settling of intrusions at depth may reset (to zero) the most thermally sensitive geochronometers in their thermal aureoles.

Finally, in recent mountain belts with still elevated reliefs, as the Alps or Himalayas, the FT cooling ages of minerals with low closing temperatures (e.g. apatites with $\sim 100^{\circ} \mathrm{C}$ ) are very sensitive to geomorphology. It is well known that samples taken horizontally below a massif (in tunnels) show youngest apatites Fr ages where the rock cover is most important. In these conditions, only a careful and detailed sampling can lead to meaningful interpretation of cooling ages in terms of tectonic and uplift history of a given area (Wagner et al 1977).

In conclusion, provided that precautions are taken in the handling of geochronological data (Baksi and Poupeau 1981), the FT method can contribute usefully to the deciphering of the cooling history of segments of the terrestrial crust. 


\section{Summary and conclusions}

An analysis of the fission track dating method has been made through a survey of the recent literature from the point of view of precision, accuracy, and the meaning of FT ages. The results of this work can be summarized as follows:

(i) The use of a stepwise dating plateau method allows a high degree of precision on FT ages to better than $\pm 5 \%(2 \sigma)$ to be obtained, regardless of the presence or not of partial fossil track fading. From our experience, the isochronal plateau method, when applicable, is to be preferred, as it gives additional information on (a) the accuracy of fission track identification, and (b) indirectly, the variability of the geological closing temperature of a given mineral phase (Poupeau 1981a; Poupeau et al 1980a). The isothermal plateau method is very useful for metamict minerals which may degrade upon heating at relatively high temperatures, as may be the case for volcanic glasses. This method proved to be the best way to date hydrated glass shards (Carpena et al 1981; this work and in preparation), otherwise found to be difficult or impossible to treat with a conventional plateau method (Naeser et al 1979).

(ii) The accuracy of FT age is strongly dependent on the choice of $\lambda_{f}$ and neutron dosimetry, both affected by unknown systematic errors. Accordingly, it has been recommended that (Naeser et al 1979; Poupeau 1981a), once a neutron dosimetry system is chosen, $\lambda_{s}$ should be considered as an operationally adjustable parameter obtained by geological calibration with well-dated volcanic rocks. Under these conditions, an accuracy of better than $5 \%$ is achievable. In order to adopt a common set of parameters in the age equation, a standardization of the neutron dosimetry would be highly desirable. The already widely distributed NBS glass standards series (Carpenter and Reimer 1974) may fulfil this role, even though suggestions were made (Workshop on Fission Track Dating, Pisa, 1980) to improve future standards.

(iii) Very often, reported FT ages cannot be used meaningfully due to the lack of appropriate information. Some suggestions for improvements of data presentation were recently made (Naeser ot al 1979). We would recommend for each FT age determination that (a) both the neutron dosimetry and ' $\lambda_{f}$ ' value be specified (with proper reference); (b) sufficient statistical data are provided: number of counting cells, total number of tracks, statistical law (and its justification) used to derive counting error, level of confidence interval on $D_{f}, D_{l}, \phi$, etc. These data are needed to compare sets of $\mathrm{FT}$ ages obtained with different irradiations and in different laboratories and also for comparing FT and other isotopic ages.

(iv) In volcanic rocks FT ages can generally be interpreted as formation ages. Their correct interpretation in other samples requires that partial track fading is taken into account in the age determination process. When a plateau method cannot be applied (due to an inhomogeneous fission track distribution or a low track density in the samples to date), some control on the geological track annealing can still be obtained through track length or track diameter measurements. The closing temperatures of minerals for FT dating are lower $\left(\sim 300^{\circ} \mathrm{C}\right.$ to $100^{\circ} \mathrm{C}$ ) than for most other nuclear geochronometers. Therefore, when used in conjunction with other dating methods, the FT ages may allow us to gain 
some insight into the last stages of the cooling history and thermal stabilization of orogenic belts and cratons. It seems that a fine time resolution can be achieved at present with the FT method. Further improvements might include the extension of model ages to new mineral phases, a better determination of the closing temperature of minerals especially with geological calibrations following the line of Naeser $(1979,1980)$, and the search for minerals with a track retention temperature higher than $300^{\circ} \mathrm{C}$, which would allow more complete studies of the cooling history of geological systems. In this respect, quartz seems to be a good candidate (Fleischer et al 1975, table 2.4) if used as a natural external detector.

\section{Acknowledgements}

The author is grateful to Drs G Bigazzi and CW Naeser, who allowed him to reproduce some of their still unpublished data. Several graduate students, J Carpena, V K Ceylan, D Chaillou, and D Vincent, and Dr Ph Romary helped in track measurements. He thanks Drs A Baksi, S Carpenter, Prot. K K Nagpaul, and Dr K K Sharma for discussions and Drs S Carpenter, J N Goswami, R S Rajan, and A S Tamhane for their comments on the manuscript.

This article was written in Ahmedabad during a stay at the Physical Research Laboratory. The author wishes to thank Prof. D Lal, Director of PRL, and his colleagues in the Geophysics Group for their hospitality and very stimulating discussions.

The final version of this manuscript was prepared at the Department of Terrestrial Magnetism, Carnegie Institution of Washington, D. C. The author wishes to thank its Director, Dr G Wetherill, and Dr R S Rajan for their encouragements and for having provided him all facilities for his work at DTM.

This work was supported by the Centre National de la Recherche Scientifique (France) and the Council of Scientific and Industrial Research (India).

\section{References}

Arias C, Bigazzi G and Bonadonna F P 1981 Nuclear Tracks 5129

Baksi A K and Poupeau G 1981 submitted to Tectonophysics.

Bhandari N, Bhat S G, Lal D, Rajagopalan G, Tamhane A S and Venkatavaradan V S 1971 Nature 230219

Bigazzi G 1981 Nuclear Tracks 535

Bevington P R 1969 Data reduction and error analysis for the physical sciences (New York: McGraw Hill) p. 336.

Carpena J 1980 3rd Cycle Thesis Montpellier University p. 112

Carpena J, Mailhe D, Naeser C W and Poupeau G 1979 C. R. Acad Sci. Paris D289 829

Carpena J, Chaillou D, Chambaudet A and Poupeau G 1980 In Solid state nuclear track detectors (New York: Pergamon) p. 961

Carpena J, Mailhe D, Poupeau G and Vincent D 1981 Nuclear Tracks (in press)

Carpenter B S 1980 Preprint

Carpenter B S and Reimer G M 1974 NBS Special Publication 260-49 P. 1.

Cowan G A and Adlet H H 1976 Geochim. Cosmochim. Acta 401487

Dakowski M, Burchart J and Galaska J 1974 Bull. Acad. Pol. Sci. 2211 
Dodson M H 1979 in Lectures in isotope geology (Berlin: Springer Verlag) p. 207

Faure 1979 Principles of Isotope geology (New York: John Wiley ), p. 464

Fleischer R L and Price P B 1964 Phys. Rev. B133 63

Fleischer R L, Price P B and Walker R M 1975 Nuclear tracks in solids: Principles and applicaitions (Berkeley: University of California Press), p. 605

Galliker D, Hugentobler E and Hahan B 1970 Helv. Phys. Acta 43593

Gleadow A J W and Lovering J F 1977 Nuclear Track Detection 199

Gleadow A J W and Duddy I R 1980 Workshop on fission track dating Pisa Sept. 10-12 (Abstract).

Haack U 1977 Am. J. Sci. 277459

Hay R L 1980 Nature (London) 284401

Hurford A J and Gleadow A J W 1977 Nuclear Track Detection 141

Hurford A J and Green S 1980 Workshop on fission track dating Pisa September 10-12 (Abstract)

Jaffey A H, Flynn K F, Glendenin L C, Bentley W C and Essling A M 1971 Phy's. Rev. C4 1889

Johnson N M, McGee V E and Naeser C W 1979 Nuclear Tracks 393

McGee V E and Johnson N M 1979 Math. Geol. 11255

Mailhe D, Carpena J and Poupeau G 1980 Instituto Geografico Nacional Madrid Special Publication No. 201 p. 149

Naeser C W 1978 U S Geol. Surv. Open File Report 76-190.

Naeser C W 1979 in Lectures in isotope geology (Berlin: Springer Verlag) p. 154

Naeser C W 1980 Preprint

Naeser C W and Fleischer R L 1975 Geophy's. Res. Lett. 267

Naeser C W, Izett G A and Obradovitch J D 1980 U.S. Geol. Surv. Bull. (in press)

Naeser C W Gleadow A J W and Wagner G A 1979 Nuclear Tracks 3133

Naeser C W, Zimmerman R A and Cebula G T 1981 Nuclear Tracks 565

Nagpaul K K, Mehta P P and Gupta M L 1974 Pture Appl. Geoplys. 112140

Parshad R, Lal N and Nagpaul K K 1979 J. Geol. Soc. India 2031

Poupeau G 1981a Cienc. Cult. 33325

Poupeau G 1981 b Preprint

Poupeau G and Rajan S R 1981 Nucl. Sci. Appl. (submitted)

Poupeau G, Romary Ph and Toulhoat P 1978a U.S. Geol. Survey Open File Report No. 78.701 p. 339

Poupeau G, Toulhoat P and Romary Ph 1978b C. R. Acad. Sci. Paris D287 971

Poupeau G, Carpena J, Chambaudet A and Romary $\mathrm{Ph} 1980 \mathrm{a}$ in Solid state nuclear track detectors (New York: Pergamon) p. 965

Poupeau G, Carpena J, Mailhe D and Ceylan V K 1980b C.R Acad. Sci. Paris D290 1189

Price P B and Walker R M 1963 J. Geophys. Res. 684847

Roberts J H, Gad R and Armani R J 1968 Phys. Rev, 1741481

Saini H S and Nagpaul K K 1979 Int. J. Appl. Radiat. Isot. 30213

Sharma K K, Bal K D, Prashad, R, Lal N and Nagpaul K K 1981 Tectonophysics 70135

Storzer D 1970a Earth Planet Sci. Lett. 855

Storzer D 1970b Ph.D. Thesis (Heidelberg Univ.: West Germany)

Storzer D and Poupeau G 1973a C.R. Acad. Sci. Paris D276 137

Storzer D and Poupeau G $1973 b$ Revnion Anuelle des Sciences de la Terre (ed. Soc. Geol. France) p. 387

Storzer D and Wagner G A 1969 Earth Planet Sci. Lett. 5463

Thiel K and Herr W 1976 Earth Planet. Sci. Lett. 3050

Turner G, Enright M C and Cadogau P H 1978 Pro. Lunar Planet. Sci. 9th (New York: Pergamon) p. 989

Virk H S and Koul S L 1977 J. Phys. Earth 25177

Wagner G A 1979 in Lectures in isotope geology (Berlin: Springer Verlag), p. 170

Wagner G A 1978 Nuclear Track. Detection 251

Wagner G A, Storzer D and Keller J 1976 N.Jb. Minner Mh 84

Wagner G A, Reimer G M, Carpenter B S, Faul H, Van Der Linden R and Gijbels R 1975 Geochim. Cosmochin. Acta. 391279

Wagner G A, Reimer G M and Jayer E 1977 Mem. 1st Gool. Min. (Univ. Padova) Italy, p. 27 